\title{
Modeling Liquid-Liquid Equilibrium of Ionic Liquid Systems with NRTL, Electrolyte-NRTL, and UNIQUAC
}

\author{
Luke D. Simoni, Youdong Lin, Joan F. Brennecke and Mark A. Stadtherr* \\ Department of Chemical and Biomolecular Engineering \\ University of Notre Dame, Notre Dame, IN 46556, USA
}

July 2007

(revised, September 2007)

*Author to whom all correspondence should be addressed. Phone (574) 631-9318; Fax (574) 631-8366; Email: markst@nd.edu 


\begin{abstract}
Characterization of liquid-liquid equilibrium (LLE) in system containing ionic liquids (ILs) is important in evaluating ILs as candidates for replacing traditional extraction and separation solvents. Though an increasing amount of experimental LLE data is becoming available, comprehensive coverage of ternary liquid-phase behavior via experimental observation is impossible. Therefore, it is important to model the LLE of mixtures containing ILs. Experimental binary and ternary LLE data involving ILs can be correlated using standard excess Gibbs energy models. However, the predictive capability of these models in this context has not been widely studied. In this paper, we study the effectiveness with which excess Gibbs energy models can be used to predict ternary LLE solely from binary measurements. This is a stringent test of the suitability of various models for describing LLE in systems containing ILs. Three different excess Gibbs free energy models are evaluated: the NRTL, UNIQUAC and electrolyteNRTL (eNRTL) models. In the case of eNRTL, a new formulation of the model is used, based on a symmetric reference state. To our knowledge, this is the first time that an electrolyte excess Gibbs energy model has been formulated for and applied to the modeling of multicomponent LLE for mixtures involving ILs. Ternary systems (IL, solvent, cosolvent) exhibiting experimental phase diagrams of various types have been chosen from the literature for comparison with the predictions. Comparisons of experimental and predicted octanol-water partition coefficients are also used to evaluate the models studied.
\end{abstract}

Keywords: Liquid-liquid equilibrium; Ionic liquids; Octanol-water partition coefficients; Excess Gibbs energy models; Electrolyte models 


\section{Introduction}

An expanding field of research involves a class of tunable solvents known as room temperature ionic liquids (ILs). ILs are generally defined as organic salts with melting temperatures below $100{ }^{\circ} \mathrm{C}$. Typically, they are composed of bulky, asymmetric cations, often imidazolium- or pyridinium-based, with a wide variety of possible anions, resulting in a distribution of charge that reduces their solidification temperatures and allows many alkyl chain and functional group substitutions. Further, by choosing cations and anions for specific properties, ILs may be tailored to fit process specifications.

Scientific and industrial communities are increasingly more concerned with "green processes," prompting the search for more benign solvents. As ILs exhibit no measurable vapor pressure under most normal operating conditions, they are an attractive alternative to the conventional volatile organic solvents from an emissions standpoint. On the other hand, some ILs are toxic and have considerable mutual solubility in water, prompting concern regarding aqueous releases, ${ }^{1,2}$ and interest in octanol-water partition coefficients for ILs. ${ }^{3,4}$ This represents a particular type of ternary liquid-liquid equilibrium (LLE) problem.

ILs are being investigated for a wide variety of reaction, separation and extraction processes involving liquid-liquid phase behavior. For instance, certain ILs have been shown to selectively extract alcohols from fermentation broths and recover amino acids from aqueous media. ${ }^{5,6}$ Since the number of possible systems involving ILs is enormous, comprehensive coverage of ternary liquid-phase behavior via experimental observation is impossible. Therefore, it is important to model the LLE of mixtures containing ILs.

The modeling of LLE in general has been widely studied; however, the macroscopic modeling of LLE in mixtures involving ILs is still in its infancy. Experimental binary and ternary LLE data involving ILs can be correlated using standard excess Gibbs energy models. However, the predictive capability of these models in this context has not been widely studied. In this paper, we study the effectiveness with which excess Gibbs energy models can be used to predict ternary LLE solely from binary measurements. This is a stringent test of the suitability of various models for describing LLE in systems containing ILs.

Three different excess Gibbs free energy models are evaluated: the NRTL, UNIQUAC and electrolyte-NRTL (eNRTL) models. In the case of eNRTL, a new formulation of the model is used, based on a symmetric reference state. Ternary systems (IL, solvent, cosolvent) 
exhibiting experimental phase diagrams of various types ${ }^{7}$ have been chosen from the literature for comparison with the predictions. Comparisons of experimental and predicted octanol-water partition coefficients are also used to evaluate the models used.

In the next section, we provide a brief survey of experimental measurements of LLE in ternary systems containing ILs, and discuss the correlation of this data using conventional excess Gibbs energy models. This is followed by a discussion of the models studied in this work, including the presentation of a new formulation for the electrolyte NRTL model. Next, in Section 3, the computational methods used in this study are described and several examples are presented in which experimental ternary LLE results, either phase diagrams or octanol-water partition coefficients, are compared to model predictions made solely from binary data.

\section{Background}

\subsection{Multicomponent LLE Data Correlations}

Three-component LLE data has been presented for $\mathrm{IL} /$ water/alcohol, ${ }^{8-10}$ IL/aromatic/aliphatic, ${ }^{11-17}$ IL/ether/alcohol, ${ }^{18}$ and IL/ether/water ${ }^{19}$ systems. Most LLE data for systems involving ILs are accompanied by correlations based on excess Gibbs energy models. In most cases the NRTL model is used, though the use of UNIQUAC has also been explored. ${ }^{20}$ Data are commonly correlated, as in the above cases, by minimizing an objective function based on the squared differences between calculated and experimental compositions, and in all cases, the six binary parameters needed are fit to the ternary data, usually resulting in a very good representation of the data. ${ }^{21,22}$ However, the binary interaction parameters determined in this way are not unique and cannot be used for prediction of other systems. Models based on binary interaction parameters are most useful when the parameters are determined from binary data and when they can be used to predict the phase behavior of a wide range of multicomponent systems containing those binaries. ${ }^{23}$ We are aware of only one study ${ }^{24}$ in which binary parameters were used to predict multicomponent LLE involving ILs. Unfortunately, full experimental ternary diagrams were not available for the two systems modeled in that study, so the quality of the predictions from the NRTL equation could not be adequately assessed.

Excess Gibbs energy models for electrolytes have not been used to date for correlation of LLE data in systems containing ILs. Usually these models have been applied to much different 
situations, primarily to relatively dilute electrolyte solutions that would solidify at higher concentrations under normal operating conditions. Thus, conventional electrolyte models have unsymmetric reference states, with the activity coefficient of the solvent and cosolvents taken to be one when they are pure, but with the activity coefficient of the salt taken to be one at infinite dilution. One popular model is the electrolyte-NRTL model (eNRTL) and its extensions, which have been used to correlate LLE data for a variety of dilute salt/mixed solvent systems. ${ }^{25,26}$ Here we reformulate the eNRTL model to have symmetric reference states, so that it can be applied to systems containing ILs across the entire composition range. To our knowledge, this is the first time that an electrolyte excess Gibbs energy model has been formulated for and applied to the modeling of multicomponent LLE for mixtures involving ILs.

\subsection{Excess Gibbs Energy Models}

The three excess Gibbs energy models considered here for modeling LLE in systems containing ILs are the NRTL, ${ }^{27}$ UNIQUAC, ${ }^{28}$ and eNRTL ${ }^{29}$ models. The first two are standard molecular models that are described briefly below, along with a discussion of how we have modified the UNIQUAC relative area parameter to permit liquid phase splitting in the systems of interest. The formulation of the symmetrically-referenced eNRTL model is then developed in more detail. Since the computation of phase stability and equilibrium (at constant $T$ and $P$ ) requires an expression for the Gibbs energy of the system as a function of composition, we focus on these expressions.

\subsubsection{Molecular Models (NRTL and UNIQUAC)}

The NRTL and UNIQUAC models were not originally intended for systems involving electrolytes. Nevertheless, they have been widely used in modeling both LLE and VLE in a variety of electrolyte systems. For example, as discussed above, they have proven to adequately correlate multicomponent LLE data for systems containing ILs. Therefore, we wish to see how these models predict multicomponent LLE data from model parameters estimated from binary data. In these two models, the ILs present are assumed to be completely associated. In other words, each cation is completely paired with an anion, and that pair is considered a single molecular species in the solution. If the reference states are taken to be pure liquids of all 
species at system $T$ and $P$, then the total Gibbs energy (per mole of mixture) is given by the molar Gibbs energy of mixing $g^{\mathrm{M}}$, which in this case is

$$
\frac{g^{\mathrm{M}}}{R T}=\sum_{i=1}^{n} x_{i} \ln x_{i}+\frac{g^{\mathrm{E}}}{R T},
$$

where $x_{i}$ is the observable mole fraction of component $i, g^{\mathrm{E}}$ is the molar excess Gibbs energy, $R$ is the gas constant, and $n$ is the number of species present.

The NRTL model ${ }^{27}$ generally predicts large heats of mixing, characteristic of electrolyte solutions. For the NRTL model,

$$
\begin{gathered}
\frac{g^{\mathrm{E}}}{R T}=\sum_{i=1}^{n} x_{i} \frac{\sum_{j=1}^{n} \tau_{j i} G_{j i} x_{j}}{\sum_{k=1}^{n} G_{k i} x_{k}}, \\
G_{i j}=\exp \left(-\alpha_{i j} \tau_{i j}\right)
\end{gathered}
$$

and

$$
\tau_{i j}=\frac{g_{i j}-g_{j j}}{R T}=\frac{\Delta g_{i j}}{R T}
$$

Here $g_{i j}$ is an energy parameter characterizing the interaction of species $i$ and $j$, and the parameter $\alpha_{i j}=\alpha_{j i}$ is related to the nonrandomness in the mixture $\left(\alpha_{i j}=0\right.$ corresponds to complete randomness, or ideal solution). Though $\alpha_{i j}$ can be treated as an adjustable parameter, we will consider it here to be fixed, so that all of the models compared will have two adjustable parameters per binary. The binary interaction parameters $\Delta g_{i j}$ (or the equivalent $\tau_{i j}$ ) are estimated from experimental data. When binary LLE data (mutual solubilities) are used for the parameter estimation, which is the case for most of the IL/solvent and IL/cosolvent binaries encountered in this study, then the binary parameters can be determined exactly by using the equal activity equations. $^{7}$ If a model does not permit liquid phase splitting, then there will be no parameter solutions to this equation system. Following Sørenson and Arlt, ${ }^{7}$ we use $\alpha_{i j}=\alpha_{j i}=0.2$ as a base case for immiscible binaries. The values used for $\alpha_{i j}$ will be discussed in more detail in Section 3.1.1.

For the UNIQUAC model, ${ }^{28}$ 


$$
\begin{gathered}
\frac{g^{\mathrm{E}}}{R T}=\frac{g_{\text {comb }}}{R T}+\frac{g_{\text {res }}}{R T}, \\
\frac{g_{\text {comb }}}{R T}=\sum_{i=1}^{n} x_{i} \ln \frac{\Phi_{i}}{x_{i}}+5 \sum_{i=1}^{n} q_{i} x_{i} \ln \frac{\theta_{i}}{\Phi_{i}}, \\
\frac{g_{\text {res }}}{R T}=-\sum_{i=1}^{n} q_{i} x_{i} \ln \left(\sum_{j=1}^{n} \theta_{j} \tau_{j i}\right), \\
\Phi_{i}=\frac{r_{i} x_{i}}{\sum_{j=1}^{n} r_{j} x_{j}} \\
\theta_{i}=\frac{q_{i} x_{i}}{\sum_{j=1}^{n} q_{j} x_{j}}
\end{gathered}
$$

and

$$
\tau_{i j}=\exp \left(\frac{-\Delta u_{i j}}{R T}\right) .
$$

Here, $r_{i}$ and $q_{i}$ represent a relative volume and surface area, respectively, for component $i$. It follows that $\Phi_{i}$ and $\theta_{i}$ are volume and surface area fractions, respectively, for component $i$. The binary interaction parameters $\Delta u_{i j}$ (or the equivalent $\tau_{i j}$ ) are estimated from experimental data. We have found that when UNIQUAC is applied to binary systems involving an IL, it often does not permit liquid phase splitting. To allow the application of UNIQUAC to LLE for systems containing ILs, we thus follow the approach of Abreu et al. ${ }^{30}$ and redefine the reference species used for determining the relative surface areas $q_{i}$. Conventionally, this reference is the van der Waals $-\mathrm{CH}_{2}-$ group, but we have allowed the normalization of $q_{i}$ to be relative to $-\mathrm{CH}_{2}-$, water or ethanol.

\subsubsection{Electrolyte Model (eNRTL)}

We consider now a model that accounts for the fact that ILs are actually electrolytes that can ionize (dissociate) in solution. There have been very few experimental measurements of the

actual degree of dissociation in ILs. Tokuda et al. ${ }^{31,32}$ have reported fractional dissociations ranging from 0.54 to 0.76 for a number of pure ILs, and found that the fraction dissociated is a function of anion and cation type, as well as cation substituent alkyl-chain length. For example, 
1-butyl-3-methylimidazolium bis(trifluoromethylsulfonyl)imide ([bmim] $\left[\mathrm{Tf}_{2} \mathrm{~N}\right]$ ) has a reported ${ }^{33}$ fractional dissociation of 0.61. Unfortunately, there is a lack of experimental fractional dissociation data for ILs in solution; however, since pure IL is a limit in the entire composition range considered in this work, the fractional dissociation of a typical pure IL is still an important consideration. As a first step in applying electrolyte excess Gibbs energy models to systems involving ILs, we will assume here that there is complete dissociation of the IL.

Consider the general case of a mixture of multiple salts and multiple solvents, all of which are liquids at the system $T$ and $P$. Complete dissociation of all electrolytes is assumed, as represented by

$$
\text { Salt }_{i} \rightarrow v_{+, i}\left(\text { Cation }_{i}\right)^{z_{+, i}}+v_{-, i}\left(\text { Anion }_{i}\right)^{z_{-, i}}, \quad i \in \mathcal{E}
$$

where $z_{+, i}$ and $z_{-, i}$ are the ionic valencies, and $\mathcal{E}$ represents the set of all electrolyte (salt) component indices. The set of all solvent component indices is denoted $S$. We assume a mixture of $n_{i}, i \in S$, moles of solvent species and $n_{i}, i \in \mathcal{E}$, moles of electrolyte species. Since there is complete dissociation of electrolytes, the latter corresponds to $n_{+, i}=v_{+, i} n_{i}$ moles of cations and $n_{-, i}=v_{-, i} n_{i}$ moles of anions for each salt $i \in \mathcal{E}$. The total number of moles in the mixture is then $N=\sum_{i \in \mathcal{F}}\left(n_{+, i}+n_{-, i}\right)+\sum_{i \in S} n_{i}$. The actual mole fractions of the species, as they exist in a solution of completely dissociated electrolytes, are indicated by $y_{i}=n_{i} / N, i \in S, y_{+, i}=n_{+, i} / N$, $i \in \mathcal{E}$, and $y_{-, i}=n_{-, i} / N, i \in \mathcal{E}$. Thus, $\sum_{i \in \mathcal{E}}\left(y_{+, i}+y_{-, i}\right)+\sum_{i \in S} y_{i}=1$. Note that for a ternary system containing an IL, this means it is treated as involving four components, solvent, cosolvent, cation and anion. The observable mole fractions are indicated by $x_{i}=n_{i} / N_{\mathrm{O}}$, $i \in\{\mathcal{E}, S\}$, where $N_{\mathrm{O}}=\sum_{i \in\{\mathcal{E}, S\}} n_{i}$.

Conventionally, excess Gibbs energy models for electrolytes use an unsymmetric reference state consisting of pure liquid solvent components and infinitely dilute salt components. However, if a salt is an IL, it is liquid in its pure state, making it more appropriate to use a symmetric reference state in which all components are pure liquids. Thus, we present here a new formulation for electrolyte excess Gibbs energy models, in which a symmetric reference state is used. Specifically, the reference state for electrolyte components is pure dissociated liquid and for solvent components is pure liquid, all at system $T$ and $P$. For this case, 
and for any ionic valencies, the total molar Gibbs energy (relative to $N$ ) is given by (see Appendix A)

$$
\frac{g^{\mathrm{M}}}{R T}=\sum_{i \in \mathcal{E}} \frac{v_{i} y_{ \pm, i}}{v_{ \pm, i}} \ln \frac{v_{i} y_{ \pm, i}}{v_{ \pm, i}}+\sum_{i \in S} y_{i} \ln y_{i}+\frac{g^{\mathrm{E}}}{R T} .
$$

Here, \pm indicates a mean ionic quantity. For salt $i$, and some associated quantity $\zeta_{i}$, the corresponding mean ionic quantity ${ }^{34}$ is given by $\zeta_{ \pm, i}=\left(\zeta_{+, i}^{v_{+, i}} \zeta_{-, i}^{v_{-i}}\right)^{1 / v_{i}}$, with $v_{i}=v_{+, i}+v_{-, i}$. The actual mole fractions are related to the mean ionic and observable mole fractions by

$$
\begin{gathered}
y_{+, i}=\frac{v_{+, i} y_{ \pm, i}}{v_{ \pm, i}}, \quad i \in \mathcal{E}, \\
y_{-, i}=\frac{v_{-, i} y_{ \pm, i}}{v_{ \pm, i}}, \quad i \in \mathcal{E}, \\
y_{ \pm, i}=\frac{v_{ \pm, i} x_{i}}{\sum_{i \in \mathcal{E}} v_{i} x_{i}+\sum_{i \in S} x_{i}}, \quad i \in \mathcal{E}
\end{gathered}
$$

and

$$
y_{i}=\frac{x_{i}}{\sum_{i \in \mathcal{E}} v_{i} x_{i}+\sum_{i \in S} x_{i}}, \quad i \in S
$$

Note that in the case of an IL(1)/solvent(2)/co-solvent(3) system, with the IL a 1:1 electrolyte ( $v_{1}$ $=2$ and $v_{ \pm, 1}=1$ ), eq 12 reduces to

$$
\frac{g^{\mathrm{M}}}{R T}=2 y_{ \pm, 1} \ln \left(2 y_{ \pm, 1}\right)+y_{2} \ln y_{2}+y_{3} \ln y_{3}+\frac{g^{\mathrm{E}}}{R T} \text {. }
$$

The eNRTL model is an excess Gibbs energy model (for $g^{\mathrm{E}}$ in eq 17) that assumes the salts are completely dissociated. Chen et al. ${ }^{29}$ originally formulated this model for inorganic electrolytes in water using the unsymmetric electrolyte reference state convention (denoted by ${ }^{*}$ ). The model consists of a Pitzer extended Debye-Hückel expression, $g_{\mathrm{PDH}}^{\mathrm{E}^{*}}$, for the long range electrostatic contribution $^{35}$ and an NRTL-type local composition contribution, $g_{\mathrm{LC}}^{\mathrm{E}^{*}}$, for the short range interactions. ${ }^{29}$ Then, $g^{E^{*}}=g_{\mathrm{PDH}}^{\mathrm{E}^{*}}+g_{\mathrm{LC}}^{\mathrm{E}^{*}}$. More recently, Chen and Song ${ }^{36}$ have generalized this model to represent multiple electrolytes in mixed solvents, and that is the form of the model 
considered here. Note that Chen and Song also include a Born term since the infinite-dilution solution is chosen as their reference state for the electrolyte. ${ }^{36}$ However, as discussed above, for the applications of interest here, we prefer to formulate the model relative to the symmetric reference state. As a result the Born term vanishes, and we use

$$
g^{\mathrm{E}}=g_{\mathrm{PDH}}^{\mathrm{E}}+g_{\mathrm{LC}}^{\mathrm{E}} .
$$

From Chen and Song, ${ }^{36}$ a symmetrically-referenced expression for the LC contribution is

$$
\begin{aligned}
\frac{g_{\mathrm{LC}}^{\mathrm{E}}}{R T} & =\sum_{i \in S} y_{i}\left(\frac{\sum_{l \in\{\mathcal{E}, S\}} z_{l} y_{l} G_{l i} \tau_{l i}}{\sum_{k \in\{\mathcal{E}, S\}} z_{k} y_{k} G_{k i}}\right)+\sum_{i \in\{+\}} z_{i} y_{i}\left\{\sum_{j \in\{-\}}\left[\left(\frac{y_{j}}{\sum_{j^{\prime} \in\{-\}} y_{j^{\prime}}}\right) \frac{\sum_{l \in\{\mathcal{E}, S\}} z_{l} y_{l} G_{l i, j i} \tau_{l i, j i}}{\sum_{k \in\{\mathcal{E}, S\}} z_{k} y_{k} G_{k i, j i}}\right]\right\} \\
& +\sum_{i \in\{-\}} z_{i} y_{i}\left\{\sum_{j \in\{+\}}\left[\left(\frac{y_{j}}{\sum_{j^{\prime} \in\{+\}} y_{j^{\prime}}}\right) \frac{\sum_{l \in\{\mathcal{E}, S\}} z_{l} y_{l} G_{l i, j i} \tau_{l i, j i}}{\sum_{k \in\{\mathcal{E}, S\}} z_{k} y_{k} G_{k i, j i}}\right]\right\} .
\end{aligned}
$$

Here $G$ and $\tau$ refer to local binary parameters related by $G=\exp (-\alpha \tau)$ where $\alpha$ is the NRTL nonrandomness factor. These binary parameters are discussed further below. The index sets $\{+\}$ and $\{-\}$ refer to the cation and anion indices, respectively. That is $\{+\}=\{(+, i) \mid i \in \mathcal{E}\}$ and $\{-\}=\{(-, i) \mid i \in \mathcal{E}\}$. Also note that, in eq $19, z_{i}=1$ for $i \in S$.

To obtain a symmetrically-referenced expression for the PDH contribution, we renormalize $g_{\mathrm{PDH}}^{\mathrm{E}^{*}}$ relative to the symmetric reference state using

$$
\frac{g_{\mathrm{PDH}}^{\mathrm{E}}}{R T}=\frac{g_{\mathrm{PDH}}^{\mathrm{E}^{*}}}{R T}-\sum_{i \in \mathcal{F}}\left(y_{+, i} \ln \gamma_{+, i}^{* 0}+y_{-, i} \ln \gamma_{-, i}^{* 0}\right),
$$

where the superscript zero indicates evaluation at the pure dissociated liquid salt. The result of this renormalization (see Appendix B) is

$$
\begin{aligned}
\frac{g_{\mathrm{PDH}}^{\mathrm{E}}}{R T} & =-\sqrt{\frac{1000}{M}} \frac{4 A_{\phi} I_{y}}{\rho} \ln \left(1+\rho \sqrt{I_{y}}\right) \\
& +A_{\phi} \sqrt{\frac{1000}{M}} \sum_{i \in \mathcal{E}}\left\{y_{+, i}\left[\frac{2 z_{+, i}^{2}}{\rho} \ln \left(1+\rho \sqrt{I_{i}^{0}}\right)+\Gamma_{+, i}^{0}\right]\right\} \\
& +A_{\phi} \sqrt{\frac{1000}{M}} \sum_{i \in \mathcal{F}}\left\{y_{-, i}\left[\frac{2 z_{-, i}^{2}}{\rho} \ln \left(1+\rho \sqrt{I_{i}^{0}}\right)+\Gamma_{-, i}^{0}\right]\right\},
\end{aligned}
$$

where $I_{y}$ is the ionic strength 


$$
I_{y}=\frac{1}{2} \sum_{i}\left(z_{+, i}^{2} y_{+, i}+z_{-, i}^{2} y_{-, i}\right), i \in \mathcal{E}
$$

with

$$
I_{i}^{0}=\lim _{x_{i} \rightarrow 1} I_{y}, \quad i \in \mathcal{E}
$$

and

$$
\Gamma_{j, i}^{0}=\frac{z_{j, i}^{2} \sqrt{I_{i}^{0}}-2\left(I_{i}^{0}\right)^{3 / 2}}{1+\rho \sqrt{I_{i}^{0}}}, j \in\{+,-\}
$$

$A_{\phi}$ is the Debye-Hückel parameter, ${ }^{35}$ which depends on temperature and on the density and dielectric constant of the mixed solvent and is given by

$$
A_{\phi}=\frac{1}{3} \sqrt{\frac{2 \pi N_{\mathrm{A}} d}{1000}}\left(\frac{e^{2}}{\varepsilon_{0} \varepsilon k T}\right)^{3 / 2},
$$

where $N_{\mathrm{A}}$ is Avogadro's number, $d$ is the density of the solvent in $\mathrm{kg} / \mathrm{m}^{3}, e$ is the elementary charge, $\varepsilon_{0}$ is the permittivity of free space, $\varepsilon$ is the dielectric constant (relative permittivity) of the solvent, $k$ is Boltzmann's constant, and $T$ is the absolute temperature. The closest approach parameter $\rho$ is a constant, whose value will be discussed further in Section 3.6. Mixing rules for the solvent molecular weight $M$, density $d$, and dielectric constant $\varepsilon$ are $^{36}$

$$
\begin{gathered}
M=\sum_{i \in S}\left[\left(\frac{y_{i}}{\sum_{i^{\prime} \in S} y_{i^{\prime}}}\right) M_{i}\right], \\
\frac{1}{d}=\sum_{i \in S}\left[\left(\frac{y_{i}}{\sum_{i^{\prime} \in S} y_{i^{\prime}}}\right) \frac{1}{d_{i}}\right]
\end{gathered}
$$

and

$$
\varepsilon=\sum_{i \in S}\left[\left(\frac{M_{i} y_{i}}{\sum_{i^{\prime} \in S} M_{i^{\prime}} y_{i^{\prime}}}\right) \varepsilon_{i}\right] .
$$

Here eq 26 is exact and eqs 27 and 28 are approximations.

For the case of primary interest here, namely ternary IL(1)/solvent(2)/cosolvent(3) systems, application of eq 19 for the LC contribution generates the following binary interaction parameters: $\tau_{12}, \tau_{32}, \tau_{13}, \tau_{23}, \tau_{2 \mathrm{c}, \mathrm{ac}}, \tau_{3 \mathrm{c}, \mathrm{ac}}, \tau_{\mathrm{za}, \mathrm{ca}}, \tau_{3 \mathrm{a}, \mathrm{ca}}$, with the indices $\mathrm{c}=(+, 1)$ and $\mathrm{a}=(-, 1)$. 
Using the electroneutrality condition, together with the symmetry of the underlying interaction energies, it can be shown ${ }^{29,36}$ that $\tau_{2 \mathrm{c}, \mathrm{ac}}=\tau_{2 \mathrm{a}, \mathrm{ca}}=\tau_{21}$ and $\tau_{3 \mathrm{c}, \mathrm{ac}}=\tau_{3 \mathrm{a}, \mathrm{ca}}=\tau_{31}$. Note also that $\tau_{1 \mathrm{c}, \mathrm{ac}}=$ $\tau_{1 \mathrm{a}, \mathrm{ca}}=\tau_{11}=0$ and $\tau_{22}=\tau_{33}=0$. Thus we have the usual six interaction parameters for the ternary system, two for each of the three observable binary subsystems. These parameters will be estimated based on data from the binary subsystems only. For all the binaries with a miscibility gap, we will use a nonrandomness parameter of $\alpha_{i j}=0.2$ as a base case, as in the NRTL model. In terms of these binary parameters the LC contribution in the eNRTL model reduces to

$$
\begin{aligned}
\frac{g_{\mathrm{LC}}^{\mathrm{E}}}{R T} & =2 y_{ \pm}\left(\frac{y_{2} G_{21} \tau_{21}+y_{3} G_{31} \tau_{31}}{y_{ \pm}+y_{2} G_{21}+y_{3} G_{31}}\right)+y_{2}\left(\frac{2 y_{ \pm} G_{12} \tau_{12}+y_{3} G_{32} \tau_{32}}{2 y_{ \pm} G_{12}+y_{2}+y_{3} G_{32}}\right) \\
& +y_{3}\left(\frac{2 y_{ \pm} G_{13} \tau_{13}+y_{2} G_{23} \tau_{23}}{2 y_{ \pm} G_{13}+G_{23} y_{2}+y_{3}}\right) .
\end{aligned}
$$

Assuming the IL to be a $1: 1$ electrolyte $\left(v_{+, 1}=v_{-, 1}=1\right)$ with $z_{+, 1}=1$ and $z_{-, 1}=-1$, the PDH contribution in the eNRTL model becomes

$$
\frac{g_{\mathrm{PDH}}^{\mathrm{E}}}{R T}=-\frac{40}{\rho} \sqrt{\frac{10}{M}} A_{\phi} y_{ \pm} \ln \left[\frac{1+\rho \sqrt{y_{ \pm}}}{1+\rho / \sqrt{2}}\right] .
$$

This appears to be the first time that a symmetrically-referenced version of the eNRTL model has been formulated and used.

\section{Results and Discussion}

Our goal is to study the effectiveness with which the excess Gibbs energy models described above can be used to predict ternary LLE solely from binary measurements. Thus, there are two main computational problems involved: 1 . Parameter estimation from binary LLE or VLE data and 2. Computation of ternary LLE. The methods used for each of these problems are discussed in Section 3.1.

Ternary phase diagrams for six example IL/solvent/cosolvent systems were studied. There are two Type 1 systems (Section 3.2), two Type 2 (Section 3.3), one Type 2a (Section 3.4), and one Type 3b (Section 3.5). A summary of the examples considered, including the Figure numbers in which results for each are presented, is provided in Table 1. The prediction of octanol-water partition coefficients is also considered for six different ILs (Section 3.6). Note 
that most IL ternary systems of interest for liquid-liquid separations and extractions are Types 1 and 2 .

\subsection{Computational Methods}

\section{$\underline{\text { 3.1.1 Parameter Estimation }}$}

Parameter estimation must be done for two different types of binary subsystems: 1 . Binaries with a miscibility gap and 2. Binaries that are miscible liquids at all compositions. In the first case, where two liquid phases are present at equilibrium over some composition range, parameter estimation from binary LLE data is preferred. To do this, we use the method described recently by Simoni et al. ${ }^{37}$ In this method, the parameter estimation is done by solving the equal activity equations for the parameters using an interval-Newton technique, ${ }^{38,39}$ which provides a mathematically and computationally rigorous approach for determining the needed binary parameters. For the case of binaries that are completely miscible liquids, we follow Anderson and Prausnitz ${ }^{40}$ and prefer to obtain parameter estimates from high-quality VLE data at the system temperature. In general, the VLE pressure will be significantly lower than the system pressure for the ternary LLE system of interest, however LLE is typically only a weak function of pressure.

Depending on the type of data that is available, and on other factors discussed below, the procedures used to obtain binary model parameters for the completely miscible binary subsystems may vary somewhat. The parameters are obtained using the following approaches, in priority order. If a suitable set of parameters is not obtained following the first approach, then the next approach is used, and so on, until a suitable set of parameters is found. Our definition of what is not "suitable" is described below.

1. Use published binary model parameters for VLE data at the system temperature. If possible, use parameters from the DECHEMA VLE Data Series. ${ }^{41}$ Otherwise use parameters from other publications (as cited in Tables 2-4).

2. Use experimental VLE data at the system temperature and solve the binary equifugacity equations for the parameters using an interval-Newton technique. This is analogous to what is done for the binaries that exhibit a miscibility gap. ${ }^{37}$ 
3. Use experimental VLE data at the system temperature and obtain the parameters by globally minimizing a least squares objective function of the form $\Sigma_{i}\left(P^{\text {exp }}-P^{\text {calc }}\right)^{2}$ using an interval-Newton technique.

4. If the binary has a miscibility gap at a temperature relatively close to the system temperature (where the binary is completely miscible), use LLE data from the miscibility gap to obtain parameters, ${ }^{37}$ and then extrapolate with respect to temperature to obtain parameter values at the system temperature.

The method used to obtain the parameters for each of the completely miscible binaries is indicated in Tables 2-4.

For any of these approaches for obtaining the miscible binary parameters, it is possible that the set of parameters found will be unsuitable. In this case, the next approach is tried. A set of parameter values is considered unsuitable in the following cases:

1. If $\Delta g_{i j}$ for NRTL and eNRTL or $\Delta u_{i j}$ for UNIQUAC is a negative number of large magnitude. This is known ${ }^{42}$ to result in a highly distorted and unrealistic Gibbs energy vs. composition surface, whose slope changes sharply near one or both of the pure components. We require that $\Delta g_{i j}$ for NRTL and eNRTL or $\Delta u_{i j}$ for UNIQUAC be greater than $-30,000 \mathrm{~J} / \mathrm{mol}$.

2. If the resulting Gibbs energy vs. composition surface is nonconvex. This situation is clearly not suitable since we are going to use the parameters to model a completely miscible binary, and nonconvexity implies existence of a miscibility gap.

The resulting binary parameter estimates for all of the binary subsystems occurring in the ternary phase diagram examples are presented in Tables 2, 3 and 4 for the NRTL, UNIQUAC and eNRTL models, respectively. Similarly, Tables 5, 6 and 7 give the binary parameter estimates used in the octanol-water partition coefficient examples. In addition to the binary parameters $\Delta g_{i j}$ for NRTL and eNRTL and $\Delta u_{i j}$ for UNIQUAC, there are some other model parameters that must be set. These are the nonrandomness factor $\alpha_{i j}$ in NRTL and eNRTL, the closest approach parameter $\rho$ in eNRTL, and the pure component size and shape parameters in UNIQUAC.

For binary subsystems that exhibit a miscibility gap, we begin by setting $\alpha_{i j}=0.2$. However, with this value of $\alpha_{i j}$ there are some cases in which no suitable values of the binary parameters can be found. If this occurs, then we change $\alpha_{i j}$ to 0.05 and increase it in increments 
of 0.05 until a suitable parameter solution is found. If no solution is found after trying $\alpha_{i j}=0.4$, then we conclude that this binary subproblem has no suitable parameter solution. For completely miscible binary subsystems, if published binary parameters are used then the corresponding published $\alpha_{i j}$ values are used. Otherwise, we begin by setting $\alpha_{i j}=0.3$. Again, if no suitable parameter solutions are found with this value of $\alpha_{i j}$, then it is varied from 0.05 to 0.40 in increments of 0.05 until a suitable parameter solution, if any, can be found. It should be emphasized that in varying $\alpha_{i j}$ in this way, we are not attempting to use it as a tuning parameter, but varying it only to obtain a suitable solution to the parameter estimation problem. Unless otherwise noted in the Tables, $\alpha_{i j}=0.2$ for binaries exhibiting LLE, and $\alpha_{i j}=0.3$ for completely miscible binaries.

In principle the closest approach parameter $\rho$ in the eNRTL model depends on the properties of the electrolyte and on how the short-range forces are modeled. However, for simplicity in practice, it is generally taken to be a constant applicable to a wide variety of salts. In the development of the eNRTL model, ${ }^{29}$ a value of $\rho=14.9$ was used, as originally suggested by Pitzer, ${ }^{35}$ and was found to be satisfactory for a large number of aqueous inorganic electrolytes. However, since ILs such as $\left[\right.$ bmpy] $\left[\mathrm{Tf}_{2} \mathrm{~N}\right]$ involve bulky organic cations, a larger value of the closest approach parameter may be appropriate for this group of salts. Simoni et al. $^{37}$ found that when using a value of 14.9 there were some cases in which no suitable parameter solution existed for LLE, and thus they suggested using $\rho=25$. For the examples considered here, we will use $\rho=14.9$ for the ternary phase diagram examples and $\rho=25$ for the octanolwater partition coefficient examples. Subsequent work may determine whether some other value of this parameter is more appropriate for modeling systems containing ILs. The eNRTL model also requires solvent physical property data (molecular weight, density and dielectric constant) to characterize the dielectric continuum; the values used are provided in Table 8.

UNIQUAC requires for each pure component $i$, a "size" (relative volume) parameter $r_{i}$ and "shape" (relative area) parameter $q_{i}$. Table 9 shows the $r_{i}$ and $q_{i}$ values for all of the pure components used in the ternary LLE diagram predictions. For the IL species, these parameters were taken from Kato and Gmehling, ${ }^{49-51}$ who computed them using the Bondi method, except for $[\mathrm{emim}]\left[\mathrm{BF}_{4}\right]$, for which the parameters were taken from Banerjee et al. ${ }^{20}$ For the solvent and co-solvent species, these parameters were taken from standard sources. ${ }^{52-54}$ Table 9 also lists the reference species used for the relative area $q_{i}$ in each system. Traditionally, the reference species 
used has been the van der Waals $-\mathrm{CH}_{2}-$ group. ${ }^{28}$ However, as explained by Abreu et al., ${ }^{30}$ this choice may make it impossible to find a suitable binary parameter solution for modeling LLE with UNIQUAC, especially when there are components of greatly different sizes and shapes. To alleviate this problem, Abreu et al. ${ }^{30}$ chose water as an alternative reference species that allowed parameter solutions to be found. Following suit, we allow either water or ethanol as the alternative reference species. The smallest reference species that resulted in solutions to the binary parameter estimation problem was used; that is, $-\mathrm{CH}_{2}-$ was tried first, then water if necessary, and finally ethanol if necessary.

\subsubsection{Ternary LLE Computation}

In computing the ternary LLE, it is important to guarantee that the calculated phase splits correspond to stable phases. To do this, we use the approach described by Tessier et al. ${ }^{55}$ This method is based on tangent plane analysis ${ }^{53,56,57}$ and requires the rigorous global minimization of the tangent plane distance, which is done using an interval-Newton approach, which can find the global minimum in the tangent plane distance with complete certainty. For additional details on the formulation and solution of the phase stability problem in the context of LLE, see Tessier et al. $^{55}$ The approach used here differs only in that a somewhat more efficient interval-Newton algorithm $^{58}$ is used.

\subsection{Examples 1 and 2: Type 1 Systems}

Example 1 is the system 1-ethyl-3-methylimidazolium tetrafluoroborate $\left([\mathrm{emim}]\left[\mathrm{BF}_{4}\right]\right) /$ tetrahydrofuran $(\mathrm{THF}) /$ water $^{19}$ at ambient pressure and $337 \mathrm{~K}$, and Example 2 is the system 1-ethyl-3-methylimidazolium ethylsulfate ([emim] $\left.\left[\mathrm{EtSO}_{4}\right]\right)$ /ethanol $(\mathrm{EtOH}) /$ ethyl tertbutyl ether $(\mathrm{ETBE})^{18}$ at $298 \mathrm{~K}$. Both are Type 1 systems exhibiting only one binary miscibility gap. In the first example, the IL/THF binary has a miscibility gap, ${ }^{19}$ while the binaries THF/water ${ }^{7,41}$ and IL/water ${ }^{19}$ are completely miscible. In the second example, only the IL/ETBE binary exhibits a miscibility gap. ${ }^{18}$ As noted by Anderson and Prausnitz, ${ }^{40}$ the quality of the binary VLE data used to obtain model parameters for the two completely miscible binary subsystems will greatly influence the quality of model predictions for Type 1 systems, though correct qualitative results (one distinct phase envelope) are likely to be obtained. For the two 
examples considered here, the ternary LLE phase diagrams, computed using parameters obtained from binary measurements, ${ }^{7,18,19,59}$ are shown in Figures 1 and 2, along with experimental data.

For these two examples, all three of the models tested provide results that are qualitatively consistent with the experimental data. However, NRTL tends to significantly underestimate the size of the two-phase envelope. UNIQUAC does better in this regard; the entropic contribution that accounts for mixing components of greatly different size and shape predicts a greater degree of demixing. We see that the eNRTL model most accurately predicts the location of the binodal curve in Example 1 and is similar in accuracy to the UNIQUAC prediction in Example 2. In light of the fact that the phase envelopes, in both examples, reside in the vicinity of the lower dielectric solvent-rich side of the diagrams (THF- and ETBE-rich dielectric continuum side), we attribute this increased accuracy to the electrostatic contribution of the eNRTL model, as the electrostatic interactions become more prominent where the average dielectric constant is small. UNIQUAC most closely captures the correct slope of the tie lines. eNRTL more accurately predicts the plait point in Figure 1, while UNIQUAC does a better job in Figure 2. Based on these examples, we cannot recommend use of NRTL for Type 1 systems, but either UNIQUAC or eNRTL may provide useful results.

\subsection{Examples 3 and 4: Type 2 Systems}

Example 3 is the system 1-ethyl-3-methylimidazolium bis(trifluoromethylsulfonyl)imide $\left([\mathrm{emim}]\left[\mathrm{Tf}_{2} \mathrm{~N}\right]\right) /$ benzene/hexane $^{11}$ and Example 4 is the system 1-decyl-3-methylimidazolium bis(trifluoromethylsulfonyl)imide $\left([\mathrm{dmim}]\left[\mathrm{Tf}_{2} \mathrm{~N}\right]\right) /$ benzene/hexane, ${ }^{12}$ both at $298 \mathrm{~K}$ and ambient pressure. These systems have two binary subsystems that have miscibility gaps, namely IL/benzene and IL/hexane, with the third (benzene/hexane) being completely miscible. Thus, the ternary LLE will be either Type 2 (a single two-phase envelope) or Type 2 a (two distinct twophase envelopes). Experimentally these have both been shown ${ }^{11,12}$ to be Type 2. For these two examples, the ternary LLE phase diagrams predicted from the binary data, ${ }^{7,11,12}$ together with experimental data from Arce et al., ${ }^{11,12}$ are given in Figures 3 and 4. These show computed results from the NRTL and UNIQUAC models. For these systems, eNRTL was not used since suitable parameter solutions were not found for the IL/benzene binary subsystems for $\rho=14.9$ or $\rho=25$. This is perhaps not surprising, considering the small dielectric constant of benzene. Similarly, eNRTL would likely paint a less realistic picture for systems of ILs with aliphatic and 
aromatic hydrocarbons, due to the small dielectric constant of the mixed-solvent. Since mixed solvents with small dielectric constants would promote ion-pairing (or grouping), it is assumed that eNRTL is less appropriate for these types of systems. By using much larger values of $\rho$, it is possible to obtain stable eNRTL parameter solutions for the IL/benzene binaries. However, a detailed study of the effect of $\rho$ in modeling LLE, and determination of a generally appropriate value for systems involving ILs, is outside the scope of this contribution.

As seen in Figures 3 and 4, both NRTL and UNIQUAC correctly predict Type 2, and not Type 2a, behavior. However, UNIQUAC is significantly better in predicting the slope of the tie lines. Note that in Figure $3\left([\mathrm{emim}]\left[\mathrm{Tf}_{2} \mathrm{~N}\right]\right)$ the slope of the UNIQUAC tie lines are in excellent agreement with experiment, and the location of the UNIQUAC solutrope (where the tie line slope changes sign) is approximately the same as that observed experimentally. Both NRTL and UNIQUAC provide a fairly accurate binodal curve in Figure 3, but due to the better prediction of tie lines UNIQUAC is clearly the better model. For $[\mathrm{dmim}]\left[\mathrm{Tf}_{2} \mathrm{~N}\right]$ in Figure 4 , we see that the UNIQUAC tie line slopes and solutrope are much more accurate than those predicted by NRTL, although there is some discrepancy with experimental values. Here, UNIQUAC also provides a much better prediction of the binodal curve than NRTL. As with the Type 1 examples, we attribute the improved accuracy of UNIQUAC compared to NRTL to the UNIQUAC entropic contribution, which is important due to the substantially different physical dimensions of the molecules encountered in the first four examples.

\subsection{Example 5: Type 2a Systems}

Example 5 is the system 1-butyl-3-methylimidazolium hexafluorophosphate $\left([\mathrm{bmim}]\left[\mathrm{PF}_{6}\right]\right) / \mathrm{EtOH} /$ water $^{8}$ at ambient pressure and at three different temperatures, 290, 298 and $313 \mathrm{~K}$. As in the previous two examples, this system has two binary subsystems that have miscibility gaps, namely $\mathrm{IL} /$ water $^{60,61}$ and $\mathrm{IL} / \mathrm{EtOH}^{8},{ }^{8}$ with the third (water/EtOH) being completely miscible. ${ }^{41,43}$ However, in this case, the experimental ternary LLE behavior is Type 2a, not Type 2. Type 2a systems have two distinct two-phase envelopes, with miscibility at intermediate compositions. Systems of this type are generally difficult to model predictively, but are also less important in the realm of liquid-liquid separations. Figure 5 shows the predictions from binary data $8,41,43,60,61$ from the NRTL and eNRTL models, along with the experimental ternary data, for the $298 \mathrm{~K}$ case. We were not able to apply UNIQUAC for this system since 
suitable binary parameter solutions could not be found (at any of the three temperatures) for all of the binary subsystems, even using the largest reference species (ethanol) for the UNIQUAC shape parameters. In Figure 5 (as well as subsequent Figures 6 and 7), there are small discrepancies between the experimental and calculated binary miscibility gaps. This is due solely to inconsistency between the experimental binary data used to perform the predictions and the experimental ternary data used for comparison.

As seen in Figure 5, NRTL and eNRTL both incorrectly predict Type 2, not Type 2a, behavior at $298 \mathrm{~K}$, and thus are qualitatively incorrect. However, eNRTL does show a narrowing of the phase envelope at intermediate compositions, suggesting a tendency to predict greater miscibility in that region. This necking of the phase envelope occurs closer to the EtOHrich side of the diagram (the region with a lower average dielectric constant). This suggests that the electrostatic contribution of the eNRTL equation promotes predictions of greater miscibility. Indeed, at $313 \mathrm{~K}$, eNRTL does predict Type $2 \mathrm{a}$ behavior, as seen in Figure 6, which shows predictions from eNRTL and experimental data $^{8}$ at all three temperatures. Figure 7 shows the same for the NRTL model. NRTL predicts Type 2 ternary behavior for all three temperatures, with the narrowing of the predicted phase envelope a result solely of the experimental binary miscibility gaps decreasing as a function of increasing temperature. On the other hand, eNRTL shows a narrowing and eventual split of the single two-phase region, in an upper critical solution temperature (UCST) somewhere between 298 and $313 \mathrm{~K}$. The experimental data suggests that there may be an UCST at a temperature somewhat less than 290 K. From this example, it appears that the eNRTL model may yield better predictions for systems with multiple binary immiscibility gaps and miscible intermediate regions.

\subsection{Example 6: Type 3b System}

Example 6 is the system 1-butyl-3-methylimidazolium bis(trifluoromethylsulfonyl)imide $\left([\right.$ bmim $\left.]\left[\mathrm{Tf}_{2} \mathrm{~N}\right]\right) / n$-butanol $(\mathrm{BuOH}) /$ water at $288 \mathrm{~K}$ and ambient pressure. ${ }^{9} \mathrm{In}$ this system, all three binary subsystems have a miscibility gap. There are multiple types of possible ternary behavior for the case of three binary miscibility gaps. ${ }^{7}$ Experimentally, this system is Type $3 b$, having three distinct two-phase envelopes, with miscibility at intermediate compositions. Using the binary data, ${ }^{7,9,62}$ predictions of the ternary phase behavior were made using NRTL, 
UNIQUAC and eNRTL, as shown in Figures 8, 9 and 10, respectively, along with the experimental ternary data.

As can be seen from Figures 8-10, none of the models correctly predicts Type $3 b$ behavior. NRTL predicts Type 3 behavior, characterized by a three-phase region bounded by three two-phase envelopes that extend to the three sides of the diagram. UNIQUAC also predicts Type 3 behavior, though with a much smaller three-phase region. eNRTL comes closest to the experimental observations, predicting Type 3a behavior, with no three-phase region and two two-phase regions. Although not qualitatively correct in terms of the LLE type, the eNRTL model does predict larger regions of complete miscibility, particularly in the lower dielectric (BuOH-rich) region of the diagram, as it did in the previous examples. Again, the tendency for the eNRTL model to predict greater miscibility at intermediate compositions and better overall accuracy can be attributed to the electrostatic term.

\subsection{Octanol-Water Partition Coefficients $\left(K_{\text {ow }}\right)$}

An octanol-water partition coefficient $\left(K_{\text {ow }}\right)$ indicates the partitioning of an infinitely dilute solute between equilibrated $n$-octanol-rich and water-rich phases at room temperature. It is commonly used in correlations of bioaccumulation in the environment. A $K_{\text {ow }}$ represents one tie-line, corresponding to an extremely low solute concentration, on a ternary solute/noctanol/water phase diagram. Therefore, phase equilibrium calculations for IL/n-octanol/water ternary systems can provide $K_{\text {ow }}$ approximations. A number of experimental $K_{\text {ow }}$ measurements are now available for ILs, ${ }^{3}$ with which we can perform comparisons. The binary interaction parameters, UNIQUAC size and shape parameters, ${ }^{49-51}$ and solvent mixture dielectric and physical parameters corresponding to these systems can be found in Tables 5-8. After computing a tie line at very dilute IL concentration at ambient temperature, the octanol-water partition coefficient can be calculated rrom $^{3}$

$$
K_{\mathrm{OW}}=\frac{C_{\mathrm{IL}}^{\text {oct }}}{C_{\mathrm{IL}}^{\text {water }}}=\frac{8.37 x_{\mathrm{IL}}^{\text {oct }}}{55.5 x_{\mathrm{IL}}^{\text {water }}},
$$

where $C_{\mathrm{IL}}^{\text {oct }}$ is the concentration of IL in the octanol-rich phase, $C_{\mathrm{IL}}^{\text {water }}$ is the concentration of IL in the aqueous phase, $x_{\mathrm{IL}}^{\text {oct }}$ is the mole fraction of $\mathrm{IL}$ in the octanol-rich phase, and $x_{\mathrm{IL}}^{\text {water }}$ is the mole fraction of IL in the aqueous phase. Using parameters obtained from binary data, 7,61-64 NRTL, UNIQUAC and eNRTL were used to predict the $K_{\mathrm{ow}}$ for several imidazolium-based ILs 
containing the $\left[\mathrm{Tf}_{2} \mathrm{~N}\right]^{-}$and $\left[\mathrm{BF}_{4}\right]^{-}$anions. The results are shown in Table 10, along with experimental values. Predictions could not be made with UNIQUAC for $[\mathrm{hmim}]\left[\mathrm{BF}_{4}\right]$ and [omim] $\left[\mathrm{BF}_{4}\right]$ since for these ILs no suitable UNIQUAC binary parameter solutions existed for the IL/water binaries. The experimental values ${ }^{3}$ for the $\left[\mathrm{Tf}_{2} \mathrm{~N}\right]^{-}$-based ILs span a range since the $K_{\mathrm{ow}}$ values were sensitive to IL concentration even when very dilute concentrations were used.

As seen in Table 10, the eNRTL model provides quite good predictions, with UNIQUAC not as good, and NRTL the worst, showing too high a sensitivity to the alkyl chain length on the cation, however the latter two models still provided close to order-of-magnitude estimates, which are sufficient for many purposes. For $[\mathrm{hmim}]\left[\mathrm{BF}_{4}\right]$ and $[\mathrm{omim}]\left[\mathrm{BF}_{4}\right]$ there are no experimental values with which to compare the model predictions. However, the experimental $K_{\mathrm{ow}}$ value $^{3}$ for [bmim] $\left[\mathrm{BF}_{4}\right]$ is $0.0030 \pm 0.0002$, which suggests that the model predictions are quite reasonable. Predictions for the $[\mathrm{bmim}]\left[\mathrm{BF}_{4}\right]$ system were not made due to insufficient binary subsystem data.

It should be noted that, for the eNRTL model, a closest approach parameter value of $\rho=$ 25 was used for all $K_{\mathrm{ow}}$ predictions. Use of the original value of $\rho=14.9$ did not result in any parameter solutions for some of the binary parameter estimation problems. The original value of $\rho=14.9$ was estimated by regressing data for small inorganic electrolytes, which probably have smaller distances of "closest approach". ${ }^{29,35}$ Thus, it is reasonable to speculate that larger organic electrolytes should have a larger value of $\rho$. The larger value of $\rho=25$ was chosen arbitrarily by Simoni et al. ${ }^{37}$ As noted in Sections 3.1.1 and 3.3, it is possible that even larger values should be used. Subsequent work may determine if some other value of the closest approach parameter in the eNRTL model is more appropriate for modeling systems containing ILs.

\section{Concluding Remarks}

In this work we have evaluated the capability of the NRTL, UNIQUAC and eNRTL models to predict, using binary (and pure) component data only, the ternary LLE of systems containing ILs. We have formulated a new symmetrically-referenced version of the eNRTL model that is suitable for these systems, in which the electrolyte is liquid in the pure state. For the prediction of ternary phase diagrams, none of the models tested was completely satisfactory, especially for the case in which all three binary subsystems have a miscibility gap. However, for other cases, both UNIQUAC and eNRTL provided potentially useful results. A difficulty is that 
it was not possible in all cases to obtain binary model parameters from the experimental binary data, despite allowing some flexibility in the choices of the NRTL nonrandomness factor, the eNRTL closest approach parameter, and the UNIQUAC shape parameter reference species. For the prediction of octanol-water partition coefficients, the eNRTL model was especially effective, and the other models still provided close to order-of-magnitude estimates, which are sufficient for many purposes. The prediction of ternary LLE from binary data only is known to be difficult, even for systems not containing ILs, and so, in some sense, the predictions obtained were surprisingly good. However, it is clear that none of the models tested fully captures the underlying physical situation, which includes partial dissociation to different extents in different phases. Thus, there remains much potential for improvement in macroscopic models for phase equilibrium involving ILs.

\section{Acknowledgements}

This work was supported in part by the National Oceanic and Atmospheric Administration under Grant NA050AR4601153 and by the Department of Energy under Grant DE-FG02-05CH11294. Additional support was provided by a University of Notre Dame Arthur J. Schmitt Presidential Fellowship (LDS). 


\section{Appendix A}

In this Appendix, we explain the development of eq 12, which gives the Gibbs energy for

a mixture of electrolyte (salt) species and solvent species. See Section 2.2.2 for the notation and nomenclature used here.

The total Gibbs energy (assuming complete dissociation of salts) can be expressed in terms of chemical potentials as

$$
G=\sum_{i \in \mathcal{E}}\left(n_{+, i} \mu_{+, i}+n_{-, i} \mu_{-, i}\right)+\sum_{i \in S}\left(n_{i} \mu_{i}\right)
$$

or

$$
\begin{aligned}
G & =\sum_{i \in \mathcal{F}}\left(n_{+, i}\left[\mu_{+, i}^{0}+R T \ln \left(\gamma_{+, i} \frac{y_{+, i}}{y_{+, i}^{0}}\right)\right]+n_{-, i}\left[\mu_{-, i}^{0}+R T \ln \left(\gamma_{-, i} \frac{y_{-, i}}{y_{-, i}^{0}}\right)\right]\right) \\
& +\sum_{i \in S}\left(n_{i}\left[\mu_{i}^{0}+R T \ln \left(\gamma_{i} \frac{y_{i}}{y_{i}^{0}}\right)\right]\right),
\end{aligned}
$$

where the superscript zero indicates a reference state quantity.

For the solvent species, we define the reference state to be the pure liquid at system $T$ and $P$. That is, $\mu_{i}^{0}=0$ at $y_{i}^{0}=1, i \in S$. For the anions and cations, we define the reference state to be pure dissociated liquid salt at system $T$ and $P$. That is, $\mu_{+, i}^{0}=\mu_{-, i}^{0}=0$ at $x_{i}^{0}=1, i \in \mathcal{E}$, which (using eqs 13, 14 and 15) corresponds to $y_{+, i}^{0}=v_{+, i} / v_{i}, y_{-, i}^{0}=v_{-, i} / v_{i}, i \in \mathcal{E}$.

Expressed relative to this reference state, the total molar Gibbs energy (relative to $N$ ) of the system is then

$$
\frac{g^{\mathrm{M}}}{R T}=\sum_{i \in \mathcal{E}}\left[y_{+, i} \ln \left(\nu_{i} \gamma_{+, i} \frac{y_{+, i}}{v_{+, i}}\right)+y_{-, i} \ln \left(\nu_{i} \gamma_{-, i} \frac{y_{-, i}}{v_{-, i}}\right)\right]+\sum_{i \in S}\left[y_{i} \ln \left(\gamma_{i} y_{i}\right)\right] .
$$

Using eqs 13 and 14 for $y_{+, i}$ and $y_{-, i}$ in terms of $y_{ \pm, i}$, along with the definitions of $y_{ \pm, i}$ and $v_{ \pm, i}$, this can be expressed as

$$
\frac{g^{\mathrm{M}}}{R T}=\sum_{i \in \mathcal{E}}\left[\frac{v_{i}}{v_{ \pm, i}} y_{ \pm, i}\left(\ln \gamma_{ \pm, i} y_{ \pm, i}+\ln \frac{v_{i}}{v_{ \pm, i}}\right)\right]+\sum_{i \in S}\left[y_{i} \ln \left(\gamma_{i} y_{i}\right)\right] .
$$

The excess Gibbs energy contributions in eq A4 are 


$$
\frac{g^{\mathrm{E}}}{R T}=\sum_{i \in \mathcal{F}}\left[\frac{v_{i} y_{ \pm, i}}{v_{ \pm, i}} \ln \left(\gamma_{ \pm, i}\right)\right]+\sum_{i \in \mathcal{S}}\left[y_{i} \ln \left(\gamma_{i}\right)\right]
$$

Thus,

$$
\frac{g^{\mathrm{M}}}{R T}=\sum_{i \in \mathcal{E}}\left[\frac{v_{i} y_{ \pm, i}}{v_{ \pm, i}} \ln \left(\frac{v_{i}}{v_{ \pm, i}} y_{ \pm, i}\right)\right]+\sum_{i \in S}\left[y_{i} \ln \left(y_{i}\right)\right]+\frac{g^{\mathrm{E}}}{R T}
$$

which appears as eq 12 in the text. 


\section{Appendix B}

In this Appendix, we explain the development of eq 21, which provides a symmetricallyreferenced expression for the Pitzer extended Debye-Hückel (PDH) contribution to the eNRTL model. See Section 2.2.2 for the notation and nomenclature used here.

To obtain a symmetrically-referenced expression for the PDH contribution, we

renormalize $g_{\mathrm{PDH}}^{\mathrm{E}^{*}}$ relative to the symmetric reference state using eq 20 in the text (renumbered as eq $\mathrm{B} 1$ here)

$$
\frac{g_{\mathrm{PDH}}^{\mathrm{E}}}{R T}=\frac{g_{\mathrm{PDH}}^{\mathrm{E}^{*}}}{R T}-\sum_{i \in \mathcal{E}}\left(y_{+, i} \ln \gamma_{+, i}^{* 0}+y_{-, i} \ln \gamma_{-, i}^{* 0}\right),
$$

where the superscript zero indicates evaluation at the pure salt limit. From Chen and Song, ${ }^{36}$ we have the unsymmetrically-referenced expression

$$
\frac{g_{\mathrm{PDH}}^{\mathrm{E}^{*}}}{R T}=-\sqrt{\frac{1000}{M}} \frac{4 A_{\phi} I_{y}}{\rho} \ln \left(1+\rho \sqrt{I_{y}}\right)
$$

and the corresponding unsymmetrically-referenced activity coefficient for ion $j$ in salt $i$

$$
\ln \gamma_{j, i}^{*}=-\sqrt{\frac{1000}{M}} A_{\phi}\left[\frac{2 z_{j, i}^{2}}{\rho} \ln \left(1+\rho I_{y}^{1 / 2}\right)+\Gamma_{j, i}\right],
$$

where

$$
\Gamma_{j, i}=\frac{z_{j, i}^{2} I_{y}^{1 / 2}-2 I_{y}^{3 / 2}}{1+\rho I_{y}^{1 / 2}} .
$$

In determining eq. B3, Chen and Song ${ }^{36}$ used a simplification in which the composition dependence of the molecular weight, density and dielectric constant of the mixed solvent was not accounted for in obtaining the partial derivatives defining the activity coefficient. Evaluating eq B3 at the pure salt limit gives

$$
\ln \gamma_{j, i}^{* 0}=\left.\ln \gamma_{j, i}^{*}\right|_{x_{i}=1}=-\sqrt{\frac{1000}{M}} A_{\phi}\left[\frac{2 z_{j, i}^{2}}{\rho} \ln \left(1+\rho \sqrt{I_{i}^{0}}\right)+\Gamma_{j, i}^{0}\right],
$$

where

$$
I_{i}^{0}=\lim _{x_{i} \rightarrow 1} I_{y}
$$

and $\Gamma_{j, i}^{0}$ is $\Gamma_{j, i}$ evaluated at $I_{y}=I_{i}^{0}$. Substitution of eq B5 into eq B1 then gives 


$$
\begin{aligned}
\frac{g_{\mathrm{PDH}}^{\mathrm{E}}}{R T} & =-\sqrt{\frac{1000}{M}} \frac{4 A_{\phi} I_{y}}{\rho} \ln \left(1+\rho \sqrt{I_{y}}\right) \\
& +A_{\phi} \sqrt{\frac{1000}{M}} \sum_{i \in \mathcal{F}}\left\{y_{+, i}\left[\frac{2 z_{+, i}^{2}}{\rho} \ln \left(1+\rho \sqrt{I_{i}^{0}}\right)+\Gamma_{+, i}^{0}\right]\right\} \\
& +A_{\phi} \sqrt{\frac{1000}{M}} \sum_{i \in \mathcal{F}}\left\{y_{-, i}\left[\frac{2 z_{-, i}^{2}}{\rho} \ln \left(1+\rho \sqrt{I_{i}^{0}}\right)+\Gamma_{-, i}^{0}\right]\right\},
\end{aligned}
$$

which is eq 21 in the text. 


\section{Literature Cited}

(1) Bernot, R. J.; Brueseke, M. A.; Evans-White, M. A.; Lamberti, G. A., Acute and chronic toxicity of imidazolium-based ionic liquids on daphnia magna. Environ. Toxicol. Chem. 2005, 24, 87-92.

(2) Docherty, K. M.; Kulpa, C. F., Toxicity and antimicrobial activity of imidazolium and pyridinium ionic liquids. Green Chem. 2005, 7, 185-189.

(3) Ropel, L.; Belveze, L. S.; Aki, S.; Stadtherr, M. A.; Brennecke, J. F., Octanol-water partition coefficients of imidazolium-based ionic liquids. Green Chem. 2005, 7, 83-90.

(4) Domańska, U.; Bogel-Łukasik, E.; Bogel-Łukasik, R., 1-octanol/water partition coefficients of 1-alkyl-3-methylimidazolium chloride. Chem. Eur. J. 2003, 9, 3033-3041.

(5) Fadeev, A. G.; Meagher, M. M., Opportunities for ionic liquids in recovery of biofuels. Chem. Commun. 2001, 3, 295-296.

(6) Wang, J. J.; Pei, Y. C.; Zhao, Y.; Hu, Z. G., Recovery of amino acids by imidazolium based ionic liquids from aqueous media. Green Chem. 2005, 7, 196-202.

(7) Sørensen, J. M.; Arlt, W., Liquid-Liquid Equilibrium Data Collection. DECHEMA: Frankfurt/Main, Germany, 1979-1980.

(8) Najdanovic-Visak, V.; Esperança, J. M. S. S.; Rebelo, L. P. N.; da Ponte, M. N.; Guedes, H. J. R.; Seddon, K. R.; de Sousa, H. C.; Szydlowski, J., Pressure, isotope, and water cosolvent effects in liquid-liquid equilibria of (ionic liquid + alcohol) systems. J. Phys. Chem. B 2003, 107, 12797-12807.

(9) Najdanovic-Visak, V.; Rebelo, L. P. N.; da Ponte, M. N., Liquid-liquid behaviour of ionic liquid-1-butanol-water and high pressure $\mathrm{CO}_{2}$-induced phase changes. Green Chem. 2005, 7, 443-450.

(10) Hu, X. S.; Yu, J.; Liu, H. Z., Liquid-liquid equilibria of the system 1-(2-hydroxyethyl)-3methylimidozolium tetrafluoroborate or 1-(2-hydroxyethyl)-2,3-dimethylimidozolium tetrafluoroborate plus water plus 1-butanol at 293.15 K. J. Chem. Eng. Data 2006, 51, 691-695.

(11) Arce, A.; Earle, M. J.; Rodríguez, H.; Seddon, K. R., Separation of aromatic hydrocarbons from alkanes using the ionic liquid 1-ethyl-3-methylimidazolium bis $\{$ (trifluoromethyl) sulfonyl $\}$ amide. Green Chem. 2007, 9, 70-74. 
(12) Arce, A.; Earle, M. J.; Rodríguez, H.; Seddon, K. R., Separation of benzene and hexane by solvent extraction with 1-alkyl-3-methylimidazolium bis \{ (trifluoromethyl sulfonyl \}amide ionic liquids: Effect of the alkyl-substituent length. J. Phys. Chem. B 2007, 111, 4732-4736.

(13) Letcher, T. M.; Deenadayalu, N., Ternary liquid-liquid equilibria for mixtures of 1methyl-3-octylimidazolium chloride + benzene + an alkane at $298.2 \mathrm{~K}$ and 1 atm. $J$. Chem. Thermodyn. 2003, 35, 67-76.

(14) Letcher, T. M.; Reddy, P., Ternary (liquid + liquid) equilibria for mixtures of 1-hexyl-3methylimidazolium (tetrafluoroborate or hexafluorophosphate) + benzene + an alkane at $\mathrm{T}=298.2 \mathrm{~K}$ and $\mathrm{p}=0.1 \mathrm{MPa}$. J. Chem. Thermodyn. 2005, 37, 415-421.

(15) Selvan, M. S.; McKinley, M. D.; Dubois, R. H.; Atwood, J. L., Liquid-liquid equilibria for toluene + heptane + 1-ethyl-3-methylimidazolium triiodide and toluene + heptane + 1-Butyl-3-methylimidazolium triiodide. J. Chem. Eng. Data 2000, 45, 841-845.

(16) Meindersma, G. W.; Podt, A. J. G.; de Haan, A. B., Ternary liquid-liquid equilibria for mixtures of toluene $+n$-heptane + an ionic liquid. Fluid Phase Equilib. 2006, 247, 158168.

(17) Meindersma, G. W.; Podt, A. J. G.; de Haan, A. B., Ternary liquid-liquid equilibria for mixtures of an aromatic + an aliphatic hydrocarbon +4 methyl- $n$-butylpyridinium tetrafluoroborate. J. Chem. Eng. Data 2006, 51, 1814-1819.

(18) Arce, A.; Rodríguez, H.; Soto, A., Use of a green and cheap ionic liquid to purify gasoline octane boosters. Green Chem. 2007, 9, 247-253.

(19) Jork, C.; Seiler, M.; Beste, Y.-A.; Arlt, W., Influence of ionic liquids on the phase behavior of aqueous azeotropic systems. J. Chem. Eng. Data 2004, 49, 852-857.

(20) Banerjee, T.; Singh, M. K.; Sahoo, R. K.; Khanna, A., Volume, surface and UNIQUAC interaction parameters for imidazolium based ionic liquids via polarizable continuum model. Fluid Phase Equilib. 2005, 234, 64-76.

(21) Aznar, M., Correlation of (liquid+liquid) equilibrium of systems including ionic liquids. Braz. J. Chem. Eng. 2007, 24, 143-149.

(22) Pereiro, A. B.; Canosa, J.; Rodríguez, A., Liquid-liquid equilibria of 1,3dimethylimidazolium methylsulfate with ketones, dialkyl carbonates and acetates. Fluid Phase Equilib. 2007, 254, 150-157. 
(23) Juliá, J. A.; Barrero, C. R.; Corso, M. E.; Grande, M. d. C.; Marschoff, C. M., On the application of the NRTL method to ternary (liquid + liquid) equilibria. J. Chem. Thermodyn. 2005, 37, 437-443.

(24) Jiao, Z.; Ma, S.; Wang, B.; Wu, Y.; Zhang, Z., Correlation and predicition of liquidliquid phase equilibrium of ionic liquid-alcohol-water systems with NRTL equation. Journal of Chemical Industry and Engineering (China) 2006, 57, 2801-2805.

(25) Liu, Y.; Watanasiri, S., Representation of liquid-liquid equilbirium of mixed-solvent systems using the extended electrolyte NRTL model. Fluid Phase Equilib. 1996, 116, 193-200.

(26) Zerres, H.; Prausnitz, J. M., Thermodynamics of phase equilibria in aqueous-organic systems with salt. AIChE J. 1994, 40, 676-691.

(27) Renon, H.; Prausnitz, J. M., Local compositions in thermodynamic excess functions for liquid mixtures. AIChE J. 1968, 14, 135-144.

(28) Abrams, D. S.; Prausnitz, J. M., Statistical thermodynamics of liquid mixtures: A new expression for the excess Gibbs energy of partly or completely miscible systems. AIChE J. 1975, 21, 116-128.

(29) Chen, C.-C.; Britt, H. I.; Boston, J. F.; Evans, L. B., Local composition model for excess Gibbs energy of electrolyte solutions, Part I: Single solvent, single completely dissociated electrolyte systems. AIChE J. 1982, 28, 588-596.

(30) Abreu, C. R. A.; Castier, M.; Tavares, F. W., A phase stability analysis of the combinatorial term of the UNIQUAC model. Chem. Eng. Sci. 1999, 54, 893-896.

(31) Tokuda, H.; Hayamizu, K.; Ishii, K.; Susan, M. A. B. H.; Watanabe, M., Physicochemical properties and structures of room temperature ionic liquids. 1. Variation of anionic species. J. Phys. Chem. B 2004, 108, 16593-16600.

(32) Tokuda, H.; Hayamizu, K.; Ishii, K.; Susan, M. A. B. H.; Watanabe, M., Physicochemical properties and structures of room temperature ionic liquids. 2. Variation of alkyl chain length in imidazolium cation. J. Phys. Chem. B 2005, 109, 6103-6110.

(33) Tokuda, H.; Tsuzuki, S.; Susan, M. A. B. H.; Hayamizu, K.; Watanabe, M., How ionic are room-temperature ionic liquids? An indicator of the physicochemical properties. $J$. Phys. Chem. B 2006, 110, 19593-19600. 
(34) Robinson, R. A.; Stokes, R. H., Electrolyte Solutions. 2nd ed.; Butterworths: London, UK, 1959.

(35) Pitzer, K. S., Electrolytes. From dilute solutions to fused salts. J. Amer. Chem. Soc. 1980, 102, 2902-2906.

(36) Chen, C.-C.; Song, Y., Generalized electrolyte-NRTL model for mixed-solvent electrolyte systems. AIChE J. 2004, 50, 1928-1941.

(37) Simoni, L. D.; Lin, Y.; Brennecke, J. F.; Stadtherr, M. A., Reliable computation of binary parameters in activity coefficient models for liquid-liquid equilibrium. Fluid Phase Equilib. 2007, 255, 138-146.

(38) Kearfott, R. B., Rigorous Global Search: Continuous Problems. Kluwer Academic Publishers: Dordrecht, The Netherlands, 1996.

(39) Neumaier, A., Interval Methods for Systems of Equations. Cambridge University Press: Cambridge, UK, 1990.

(40) Anderson, T. F.; Prausnitz, J. M., Application of the UNIQUAC equation to calculation of multicomponent phase equilibria. 2. Liquid-liquid equilibria. Ind. Eng. Chem. Process Des. Dev. 1978, 17, 561-567.

(41) Gmehling, J.; Onken, U.; Arlt, W., Vapor-liquid Equilibrium Data Collection, Chemistry Data Series, Vol. I, Parts 1-8. DECHEMA: Frankfurt/Main, Germany, 1977-1990.

(42) Heidemann, R. A.; Mandhane, J. M., Some properties of the NRTL equation in correlating liquid-liquid equilibrium data. Chem. Eng. Sci. 1973, 28, 1213-1221.

(43) Kurihara, K.; Nakamichi, M.; Kojima, K., Isobaric vapor-liquid equilibria for methanol + ethanol + water and the three constituent binary systems. J. Chem. Eng. Data 1993, 38, 446-449.

(44) Critchfield, F. E.; Gibson, J. A.; Hall, J. L., Dielectric constant and refractive index from 20 to 35-degrees and density at 25-degrees for the system tetrahydrofuran-water. J. Amer. Chem. Soc. 1953, 75, 6044-6045.

(45) Smyth, C. P.; Stoops, W. N., The dielectric polarization of liquids. VI. Ethyl iodide, ethanol, normal-butanol and normal-octanol. J. Am. Chem. Soc. 1929, 51, 3312-3329.

(46) Morgan, S. O.; Yager, W. A., Dielectric properties of organic compounds relation to chemical composition and physical structure. Ind. Eng. Chem. 1940, 32, 1519-1528. 
(47) Arce, A.; Rodríguez, H.; Soto, A., Purification of ethyl tert-butyl ether from its mixtures with ethanol by using an ionic liquid. Chem. Eng. J. 2006, 115, 219-223.

(48) Fernández, D. P.; Goodwin, A. R. H.; Lemmon, E. W.; Levelt Sengers, J. M. H.; Williams, R. C., A formulation for the static permittivity of water and steam at temperatures from $238 \mathrm{~K}$ to $873 \mathrm{~K}$ at pressures up to $1200 \mathrm{MPa}$, including derivatives and Debye-Hückel coefficients. J. Phys. Chem. Ref. Data 1997, 26, 1125-1166.

(49) Kato, R.; Krummen, M.; Gmehling, J., Measurement and correlation of vapor-liquid equilibria and excess enthalpies of binary systems containing ionic liquids and hydrocarbons. Fluid Phase Equilib. 2004, 224, 47-54.

(50) Kato, R.; Gmehling, J., Measurement and correlation of vapor-liquid equilibria of binary systems containing the ionic liquids [EMIM] [(CF3SO2)(2)N], [BMIM]

[(CF3SO2)(2)N], [MMIM] [(CH3)(2)PO4] and oxygenated organic compounds respectively water. Fluid Phase Equilib. 2005, 231, 38-43.

(51) Kato, R.; Gmehling, J., Systems with ionic liquids: Measurement of VLE and gamma(infinity) data and prediction of their thermodynamic behavior using original UNIFAC, mod. UNIFAC(Do) and COSMO-RS(O1). J. Chem. Thermodyn. 2005, 37 , 603-619.

(52) Anderson, T. F.; Prausnitz, J. M., Application of the UNIQUAC equation to calculation of multicomponent phase equilibria. 1. Vapor-liquid equilibria. Ind. Eng. Chem. Process Des. Dev. 1978, 17, 552-561.

(53) Prausnitz, J. M.; Lichtenthaler, R. N.; Gomes de Azevedo, E., Molecular Thermodynamics of Fluid-Phase Equilibria. 3rd ed.; Prentice Hall: Upper-Saddle River, New Jersey, 1999.

(54) Smith, J. M.; Van Ness, H. C.; Abbott, M. M., Introduction to Chemical Engineering Thermodynamics. 6th ed.; McGraw-Hill: New York, NY, 2001.

(55) Tessier, S. R.; Brennecke, J. F.; Stadtherr, M. A., Reliable phase stability analysis for excess Gibbs energy models. Chem. Eng. Sci. 2000, 55, 1785-1796.

(56) Baker, L. E.; Pierce, A. C.; Luks, K. D., Gibbs energy analysis of phase equilibria. Soc. Petrol. Engrs. J. 1982, 22, 731-742.

(57) Michelsen, M. L., The isothermal flash problem. Part I: Stability. Fluid Phase Equilib. 1982, 9, 1-19. 
(58) Lin, Y.; Stadtherr, M. A., LP Strategy for interval-Newton method in deterministic global optimization. Ind. Eng. Chem. Res. 2004, 43, 3741-3749.

(59) Arce, A.; Martinez-Ageitos, J.; Rodil, E.; Soto, A., [EVLM1030] Vapor-liquid equilibrium in mixtures and solutions. ELDATA 1998, 4, 135.

(60) Najdanovic-Visak, V.; Esperança, J. M. S. S.; Rebelo, L. P. N.; da Ponte, M. N.; Guedes, H. J. R.; Seddon, K. R.; Szydlowskiy, J., Phase behaviour of room temperature ionic liquid solutions: an unusually large co-solvent effect in (water + ethanol). Phys. Chem. Chem. Phys. 2002, 4, 1701-1703.

(61) Anthony, J. L.; Maginn, E. J.; Brennecke, J. F., Solution thermodynamics of imidazolium-based ionic liquids and water. J. Phys. Chem. B 2001, 105, 10942-10949.

(62) Crosthwaite, J. M.; Aki, S. N. V. K.; Maginn, E. J.; Brennecke, J. F., Liquid phase behavior of imidazolium-based ionic liquids with alcohols. J. Phys. Chem. B 2004, 108, 5113-5119.

(63) Chapeaux, A.; Simoni, L. D.; Stadtherr, M. A.; Brennecke, J. F., Liquid phase behavior of ionic liquids with water and 1-octanol and modeling of 1-octanol/water partition coefficients. J. Chem. Eng. Data 2007, in press.

(64) Simoni, L. D., Liquid-liquid equilibria of 1-butyl-3-methylimidazolium 1-hexyl-2,3methylimidazolium bis(trifluoromethylsulfonyl)imide with $n$-octanol. Unpublished data, 2006. 
Table 1: System type, components, and temperature for ternary diagrams.

\begin{tabular}{|c|c|c|c|c|}
\hline $\begin{array}{l}\text { Example } \\
\text { No. }\end{array}$ & $\begin{array}{l}\text { Figure } \\
\text { No. }\end{array}$ & $\begin{array}{l}\text { Ternary } \\
\text { Type }\end{array}$ & $\begin{array}{l}\text { System } \\
(1) /(2) /(3)\end{array}$ & $\begin{array}{l}\text { Temperature } \\
(\mathrm{K})\end{array}$ \\
\hline 1 & 1 & 1 & {$[\mathrm{emim}]\left[\mathrm{BF}_{4}\right] / \mathrm{THF} /$ Water $^{19}$} & 337 \\
\hline 2 & 2 & 1 & {$[\mathrm{emim}]\left[\mathrm{EtSO}_{4}\right] /$ Ethanol/ETBE $^{18}$} & 298 \\
\hline 3 & 3 & 2 & {$[\mathrm{emim}]\left[\mathrm{Tf}_{2} \mathrm{~N}\right] /$ Benzene/Hexane ${ }^{11}$} & 298 \\
\hline 4 & 4 & 2 & {$[\mathrm{dmim}]\left[\mathrm{Tf}_{2} \mathrm{~N}\right] /$ Benzene/Hexane ${ }^{12}$} & 298 \\
\hline 5 & $5,6,7$ & $2 \mathrm{a}$ & {$[\mathrm{bmim}]\left[\mathrm{PF}_{6}\right] / \mathrm{EtOH} /$ Water $^{8}$} & $290,298,313$ \\
\hline 6 & $8,9,10$ & $3 b$ & {$[\mathrm{bmim}]\left[\mathrm{Tf}_{2} \mathrm{~N}\right] / \mathrm{BuOH} /$ Water $^{9}$} & 288 \\
\hline
\end{tabular}


Table 2: NRTL binary interaction parameters $(\mathrm{J} / \mathrm{mol})$ for ternary diagrams described in Table 1.

\begin{tabular}{|c|c|c|c|c|c|c|c|c|c|}
\hline $\begin{array}{l}\text { Example } \\
\text { No. }\end{array}$ & $\begin{array}{l}\text { Figure } \\
\text { No. }\end{array}$ & $\begin{array}{l}\text { Temp } \\
(\mathrm{K})\end{array}$ & $\Delta g_{12}$ & $\Delta g_{21}$ & $\Delta g_{13}$ & $\Delta g_{31}$ & $\Delta g_{23}$ & $\Delta g_{32}$ & $\alpha_{23}$ \\
\hline 1 & 1 & 337 & -1947.1 & 18748 & $11103^{\mathrm{d}}$ & $-5987.0^{\mathrm{d}}$ & $-509.97^{\mathrm{e}}$ & $7663.7^{\mathrm{e}}$ & $0.3^{\mathrm{e}}$ \\
\hline 2 & 2 & 298 & $4799.9^{c}$ & $-863.13^{c}$ & 4708.8 & 16153 & $-1244.3^{c}$ & $7667.6^{c}$ & $0.3^{c}$ \\
\hline 3 & 3 & 298 & -7242.1 & 28721 & 4569.2 & 19602 & $2421.0^{\mathrm{a}}$ & $-488.64^{\mathrm{a}}$ & $0.3002^{\mathrm{a}}$ \\
\hline 4 & 4 & 298 & -14287 & 31378 & -1866.7 & 23590 & $2421.0^{\mathrm{a}}$ & $-488.64^{a}$ & $0.3002^{\mathrm{a}}$ \\
\hline 5 & 5,6 & 298 & -4309.1 & 16476 & -685.01 & 16672 & $332.21^{\mathrm{a}}$ & $3350.6^{\mathrm{a}}$ & $0.2957^{\mathrm{a}}$ \\
\hline 5 & 6 & 290 & -3887.8 & 16879 & -541.50 & 16125 & $-2588.7^{b}$ & $6908.2^{\mathrm{b}}$ & $0.1448^{b}$ \\
\hline 5 & 6 & 313 & -5068.0 & 15739 & -1849.6 & 18500 & $-2493.4^{b}$ & $7102.4^{b}$ & $0.1448^{b}$ \\
\hline 6 & 8 & 288 & -3930.4 & 14143 & -443.23 & 19778 & -2555.4 & 12217 & 0.2 \\
\hline
\end{tabular}


Table 3: UNIQUAC binary interaction parameters ( $\mathrm{J} / \mathrm{mol})$ for ternary diagrams described in Table 1.

\begin{tabular}{|l|llllllll|}
\hline $\begin{array}{l}\text { Example } \\
\text { No. }\end{array}$ & Figure & Temp & & & & & & \\
& No. & $(\mathrm{K})$ & $\Delta u_{12}$ & $\Delta u_{21}$ & $\Delta u_{13}$ & $\Delta u_{31}$ & $\Delta u_{23}$ & $\Delta u_{32}$ \\
\hline 1 & 1 & 337 & -682.85 & 4646.7 & $13554^{\mathrm{c}}$ & $-9787.6^{\mathrm{c}}$ & $1826.4^{\mathrm{d}}$ & $1978.7^{\mathrm{d}}$ \\
2 & 2 & 298 & $3010.5^{\mathrm{b}}$ & $-7433.3^{\mathrm{b}}$ & 2744.8 & 21215 & $522.24^{\mathrm{b}}$ & $4467.43^{\mathrm{b}}$ \\
3 & 3 & 298 & -1820.6 & 4969.6 & 2955.2 & 4969.6 & $-66.016^{\mathrm{a}}$ & $564.67^{\mathrm{a}}$ \\
4 & 4 & 298 & -2104.9 & 3789.7 & -720.40 & 2455.2 & $-66.016^{\mathrm{a}}$ & $564.67^{\mathrm{a}}$ \\
6 & 9 & 288 & 67.986 & 1431.9 & 5811.7 & 1368.1 & 1959.4 & 2333.4 \\
\hline
\end{tabular}

$\mathrm{b}=$ Solve equifugacity conditions for VLE

$\mathrm{c}=$ Globally minimize $\Sigma\left(P^{\text {exp }}-P^{\text {calc }}\right)^{2}$ with VLE data

$\mathrm{d}=$ Extrapolate binary LLE data to miscibility at system temperature 
Table 4: eNRTL binary interaction parameters $(\mathrm{J} / \mathrm{mol})$ for ternary diagrams with $\rho=14.9$ described in Table 1 .

\begin{tabular}{|c|c|c|c|c|c|c|c|c|c|}
\hline $\begin{array}{l}\text { Example } \\
\text { No. }\end{array}$ & $\begin{array}{l}\text { Figure } \\
\text { No. }\end{array}$ & $\begin{array}{l}\text { Temp } \\
(\mathrm{K})\end{array}$ & $\Delta g_{12}$ & $\Delta g_{21}$ & $\Delta g_{13}$ & $\Delta g_{31}$ & $\Delta g_{23}$ & $\Delta g_{32}$ & $\alpha_{23}$ \\
\hline 1 & 1 & 337 & $-85648 \dagger$ & $-23947 \dagger$ & $-1697.2^{d}$ & $-693.82^{d}$ & $-509.97^{\mathrm{e}}$ & $7663.7^{\mathrm{e}}$ & $0.3^{\mathrm{e}}$ \\
\hline 2 & 2 & 298 & $-26001^{c}$ & $73882^{c}$ & $-81274 \dagger$ & $-46459 \dagger$ & $-1244.3^{c}$ & $7667.6^{\mathrm{c}}$ & $0.3^{\mathrm{e}}$ \\
\hline 5 & 5,7 & 298 & -7219.1 & 16431 & -3992.3 & 17535 & $332.21^{\mathrm{a}}$ & $3350.6^{\mathrm{a}}$ & $0.2957^{a}$ \\
\hline 5 & 7 & 290 & -6981.1 & 17322 & -3790.2 & 16938 & $-2588.7^{b}$ & $6908.2^{b}$ & $0.1448^{b}$ \\
\hline 5 & 7 & 313 & -7795.1 & 16644 & -4951.0 & 19633 & $-2493.4^{b}$ & $7102.4^{b}$ & $0.1448^{b}$ \\
\hline 6 & 10 & 288 & -40.923 & 1747.41 & -3636.3 & 20083 & -2555.4 & 12217 & 0.2 \\
\hline
\end{tabular}


Table 5: NRTL binary interaction parameters $(\mathrm{J} / \mathrm{mol})$ for the system IL(1)/octanol(2)/water(3) used for calculating $K_{\text {ow }}$ 's

\begin{tabular}{|l|llllll|}
\hline Ionic Liquid & $\Delta g_{12}$ & $\Delta g_{21}$ & $\Delta g_{13}$ & $\Delta g_{31}$ & $\Delta g_{23}$ & $\Delta g_{32}$ \\
\hline$[\mathrm{bmim}]\left[\mathrm{Tf}_{2} \mathrm{~N}\right]$ & -136.15 & 26989 & -441.82 & 19778 & 861.86 & 22421 \\
{$[\mathrm{hmim}]\left[\mathrm{Tf}_{2} \mathrm{~N}\right]$} & -1414.2 & 12741 & 702.08 & 21820 & 861.86 & 22421 \\
{$[\mathrm{omim}]\left[\mathrm{Tf}_{2} \mathrm{~N}\right]$} & -3433.0 & 13511 & 1023.9 & 22269 & 861.86 & 22421 \\
{$[\mathrm{hmmim}]\left[\mathrm{Tf}_{2} \mathrm{~N}\right]$} & -0.86950 & 19441 & 1378.3 & 22158 & 861.86 & 22421 \\
\hline$[\mathrm{hmim}]\left[\mathrm{BF}_{4}\right]$ & 586.85 & 17663 & -5992.7 & 18455 & 861.86 & 22421 \\
{$[\mathrm{omim}]\left[\mathrm{BF}_{4}\right]$} & -3426.5 & 16253 & -5007.9 & 21075 & 861.86 & 22421 \\
\hline
\end{tabular}

Table 6: UNIQUAC binary interaction parameters $(\mathrm{J} / \mathrm{mol})$ for the system IL(1)/octanol(2)/water(3) used for calculating $K_{\text {ow }}$ 's with $q_{\text {octanol }}=4.16, q_{\text {water }}=1.0, r_{\text {octanol }}=6.62$ and $r_{\text {water }}=0.92$, and water as the reference species.

\begin{tabular}{|l|llllllll|}
\hline Ionic Liquid & $\Delta u_{12}$ & $\Delta u_{21}$ & $\Delta u_{13}$ & $\Delta u_{31}$ & $\Delta u_{23}$ & $\Delta u_{32}$ & $q_{\mathrm{IL}}$ & $r_{\mathrm{IL}}$ \\
\hline$[\mathrm{bmim}]\left[\mathrm{Tf}_{2} \mathrm{~N}\right]$ & -1874.6 & 6148.7 & 6016.5 & 1416.3 & 3950.2 & 3876.3 & 7.29 & 11.2 \\
{$[\mathrm{hmim}]\left[\mathrm{Tf}_{2} \mathrm{~N}\right]$} & -568.49 & 2232.8 & 6951.4 & 1582.8 & 3950.2 & 3876.3 & 8.30 & 12.5 \\
{$[\mathrm{omim}]\left[\mathrm{Tf}_{2} \mathrm{~N}\right]$} & -685.18 & 1875.2 & 7641.1 & 1477.2 & 3950.2 & 3876.3 & 9.31 & 13.8 \\
{$[\mathrm{hmmim}]\left[\mathrm{Tf}_{2} \mathrm{~N}\right]$} & -960.84 & 3494.7 & 7707.2 & 1524.4 & 3950.2 & 3876.3 & 8.74 & 13.3 \\
\hline
\end{tabular}

Table 7: eNRTL binary interaction parameters (J/mol) for the system IL(1)/octanol(2)/water(3) used for calculating $K_{\mathrm{ow}}$ 's with $\rho=25$.

\begin{tabular}{|l|llllll|}
\hline Ionic Liquid & $\Delta g_{12}$ & $\Delta g_{21}$ & $\Delta g_{13}$ & $\Delta g_{31}$ & $\Delta g_{23}$ & $\Delta g_{32}$ \\
\hline$[\mathrm{bmim}]\left[\mathrm{Tf}_{2} \mathrm{~N}\right]$ & -5507.9 & 13835 & -3374.4 & 20401 & 861.86 & 22421 \\
{$[\mathrm{hmim}]\left[\mathrm{Tf}_{2} \mathrm{~N}\right]$} & -2339.7 & 4270.0 & -2365.1 & 21723 & 861.86 & 22421 \\
{$[\mathrm{omim}]\left[\mathrm{Tf}_{2} \mathrm{~N}\right]$} & -7208.9 & 13888 & -2072.7 & 21986 & 861.86 & 22421 \\
{$[\mathrm{hmmim}]\left[\mathrm{Tf}_{2} \mathrm{~N}\right]$} & -6609.9 & 16312 & -1774.2 & 21730 & 861.86 & 22421 \\
\hline$[\mathrm{hmim}]\left[\mathrm{BF}_{4}\right]$ & -5030.4 & 8910.5 & -6959.2 & 20473 & 861.86 & 22421 \\
{$[\mathrm{omim}]\left[\mathrm{BF}_{4}\right]$} & -7135.1 & 13929 & -6466.1 & 22669 & 861.86 & 22421 \\
\hline
\end{tabular}


Table 8: eNRTL solvent properties.

\begin{tabular}{|c|c|c|c|c|c|}
\hline Solvent & $\begin{array}{l}\text { Temp } \\
(\mathrm{K})\end{array}$ & $M$ & $d\left(\mathrm{~g} / \mathrm{cm}^{3}\right)$ & $\varepsilon$ & Reference \\
\hline tetrahydrofuran & 337 & 72.11 & 0.84 & 6.40 & Critchfield $^{44}$ \\
\hline ethanol & 290 & 46.07 & 0.78 & 24.4 & Smyth \& Stoops ${ }^{45}$ \\
\hline ethanol & 298 & 46.07 & 0.78 & 23.2 & Smyth \& Stoops ${ }^{45}$ \\
\hline ethanol & 313 & 46.07 & 0.76 & 21.0 & Smyth \& Stoops ${ }^{45}$ \\
\hline benzene & 298 & 78.10 & 0.87 & 2.3 & Robinson \& Stokes ${ }^{34}$ \\
\hline$n$-butanol & 288 & 74.12 & 0.81 & 17.8 & Smyth \& Stoops ${ }^{45}$ \\
\hline ethyl tert-butyl ether & 298 & 102.17 & 0.74 & 1.89 & Arce et $\mathrm{al}^{47}$ \\
\hline hexane & 298 & 86.17 & 0.60 & 1.89 & Morgan et al. ${ }^{46}$ \\
\hline water $^{\mathrm{a}}$ & 288 & 18.02 & 1.00 & 81.9 & Robinson \& Stokes ${ }^{34}$ \\
\hline water & 298 & 18.02 & 1.00 & 78.3 & Robinson \& Stokes ${ }^{34}$ \\
\hline water & 290 & 18.02 & 1.00 & 80.8 & Robinson \& Stokes ${ }^{34}$ \\
\hline water & 313 & 18.02 & 0.99 & 73.2 & Robinson \& Stokes ${ }^{34}$ \\
\hline water & 337 & 18.02 & 0.98 & 65.3 & Robinson \& Stokes ${ }^{34}$ \\
\hline$n$-octanol & 298 & 130.23 & 0.82 & 10.03 & Smyth \& Stoops ${ }^{45}$ \\
\hline
\end{tabular}

Table 9: UNIQUAC size and shape parameters for ternary diagrams.

\begin{tabular}{|l|lllllllll|}
\hline $\begin{array}{l}\text { Example } \\
\text { No. }\end{array}$ & Figure & Temp & UNIQUAC & & & & & & \\
\hline 1 & 1 & 337 & Water & 3.80 & 8.38 & 1.94 & 2.94 & 1.00 & 0.92 \\
2 & 2 & 298 & Ethanol & 3.66 & 7.94 & 1.00 & 2.11 & 2.12 & 4.74 \\
3 & 3 & 298 & $-\mathrm{CH}_{2}-$ & 8.78 & 9.89 & 2.40 & 3.19 & 3.86 & 4.50 \\
4 & 4 & 298 & $-\mathrm{CH}_{2}-$ & 14.5 & 15.1 & 2.40 & 3.19 & 3.86 & 4.50 \\
6 & $7,8,9$ & 288 & Water & 7.29 & 11.2 & 2.62 & 3.92 & 1.00 & 0.92 \\
\hline
\end{tabular}


Table 10: Calculated* versus experimental $K_{\text {ow }}$ using eq 31 for the system IL(1)/octanol(2)/water(3).

\begin{tabular}{|l|lll|l|}
\hline Ionic Liquid & NRTL & UNIQUAC & eNRTL & $\operatorname{Exp}^{3}$ \\
\hline$[$ bmim $]\left[\mathrm{Tf}_{2} \mathrm{~N}\right] \dagger, \ddagger$ & 0.029 & 0.23 & 0.28 & $0.11-0.62$ \\
{$[\mathrm{hmim}]\left[\mathrm{Tf}_{2} \mathrm{~N}\right] \dagger$} & 11.9 & 11.8 & 3.90 & $1.42-1.66$ \\
{$[\mathrm{omim}]\left[\mathrm{Tf}_{2} \mathrm{~N}\right] \dagger$} & 45.0 & 55.5 & 5.88 & $6.3-11.1$ \\
{$[\mathrm{hmmim}]\left[\mathrm{Tf}_{2} \mathrm{~N}\right] \dagger+\ddagger$} & 0.83 & 1.62 & 1.24 & $1.35-1.79$ \\
\hline$[\mathrm{bmim}]\left[\mathrm{BF}_{4}\right]$ & - & - & - & $0.0030 \pm 0.0002$ \\
{$[\mathrm{hmim}]\left[\mathrm{BF}_{4}\right] \dagger$} & 0.011 & - & 0.099 & - \\
{$[\mathrm{omim}]\left[\mathrm{BF}_{4}\right]$} & 0.74 & - & 0.47 & - \\
\hline
\end{tabular}

*Mole fraction of ionic liquid in overall system: $z_{1}=0.0001, z_{2}=0.4999, z_{3}=0.5000$

$\dagger \mathrm{IL} /$ water binary data from Chapeaux et al. ${ }^{63}$

$\ddagger$ IL/octanol binary data from Simoni, ${ }^{64}$ available upon request 


\section{List of Figures}

Figure 1: Type 1 system $[\mathrm{emim}]\left[\mathrm{BF}_{4}\right] /$ Tetrahydrofuran/Water at $337 \mathrm{~K}$. Experimental data from Jork et al. ${ }^{19}$ All models predict Type 1 behavior.

Figure 2: Type 1 system $[\mathrm{emim}]\left[\mathrm{EtSO}_{4}\right] /$ Ethyl tert-butyl ether/Ethanol at $298 \mathrm{~K}$. Experimental data is from Arce et al. ${ }^{18}$ All models predict Type 1 behavior.

Figure 3: Type 2 system $[\mathrm{emim}]\left[\mathrm{Tf}_{2} \mathrm{~N}\right] /$ Benzene/Hexane at $298 \mathrm{~K}$. Experimental data is from Arce et al. ${ }^{11}$ NRTL and UNIQUAC predict qualitatively correct Type 2 behavior. UNIQUAC is very accurate as well.

Figure 4: Type 2 system $[\mathrm{dmim}]\left[\mathrm{Tf}_{2} \mathrm{~N}\right] /$ Benzene/Hexane at $298 \mathrm{~K}$. Experimental data is from Arce et al. ${ }^{12}$ NRTL and UNIQUAC predict qualitatively correct Type 2 behavior. UNIQUAC is very accurate as well.

Figure 5: Type 2a system $[\mathrm{bmim}]\left[\mathrm{PF}_{6}\right] /$ Ethanol/Water at $298 \mathrm{~K}$. Experimental data from Najdanovic-Visak et al. ${ }^{8}$ NRTL and eNRTL predict qualitatively incorrect Type 2 behavior.

Figure 6: Type 2a system as $[\mathrm{bmim}]\left[\mathrm{PF}_{6}\right] /$ Ethanol/Water at 290, 298 and $313 \mathrm{~K}$. Experimental data from Najdanovic-Visak et al. ${ }^{8}$ eNRTL predicts an UCST between 298 and $313 \mathrm{~K}$, beyond which the correct Type 2a behavior is predicted.

Figure 7: Type 2a system as $[\mathrm{bmim}]\left[\mathrm{PF}_{6}\right] / E$ thanol/Water at 290, 298 and $313 \mathrm{~K}$. Experimental data from Najdanovic-Visak et al. ${ }^{8}$ NRTL predicts a Type 2 system at all temperatures.

Figure 8: Type $3 \mathrm{~b}$ system as $[\mathrm{bmim}]\left[\mathrm{Tf}_{2} \mathrm{~N}\right] / \mathrm{n}-\mathrm{Butanol} / \mathrm{W}$ ater at $288 \mathrm{~K}$. Experimental data from Najdanovic-Visak et al. ${ }^{9}$ NRTL predicts qualitatively incorrect Type 3 behavior.

Figure 9: Type $3 \mathrm{~b}$ system as $[\mathrm{bmim}]\left[\mathrm{Tf}_{2} \mathrm{~N}\right] / \mathrm{n}-\mathrm{Butanol} / \mathrm{W}$ ater at $288 \mathrm{~K}$. Experimental data from Najdanovic-Visak et al. ${ }^{9}$ UNIQUAC predicts qualitatively incorrect Type 3 behavior.

Figure 10: Type $3 \mathrm{~b}$ system as $[\mathrm{bmim}]\left[\mathrm{Tf}_{2} \mathrm{~N}\right] / \mathrm{n}-\mathrm{Butanol} /$ Water at $288 \mathrm{~K}$. Experimental data from Najdanovic-Visak et al. ${ }^{9}$ eNRTL predicts qualitatively incorrect Type 3a behavior. 


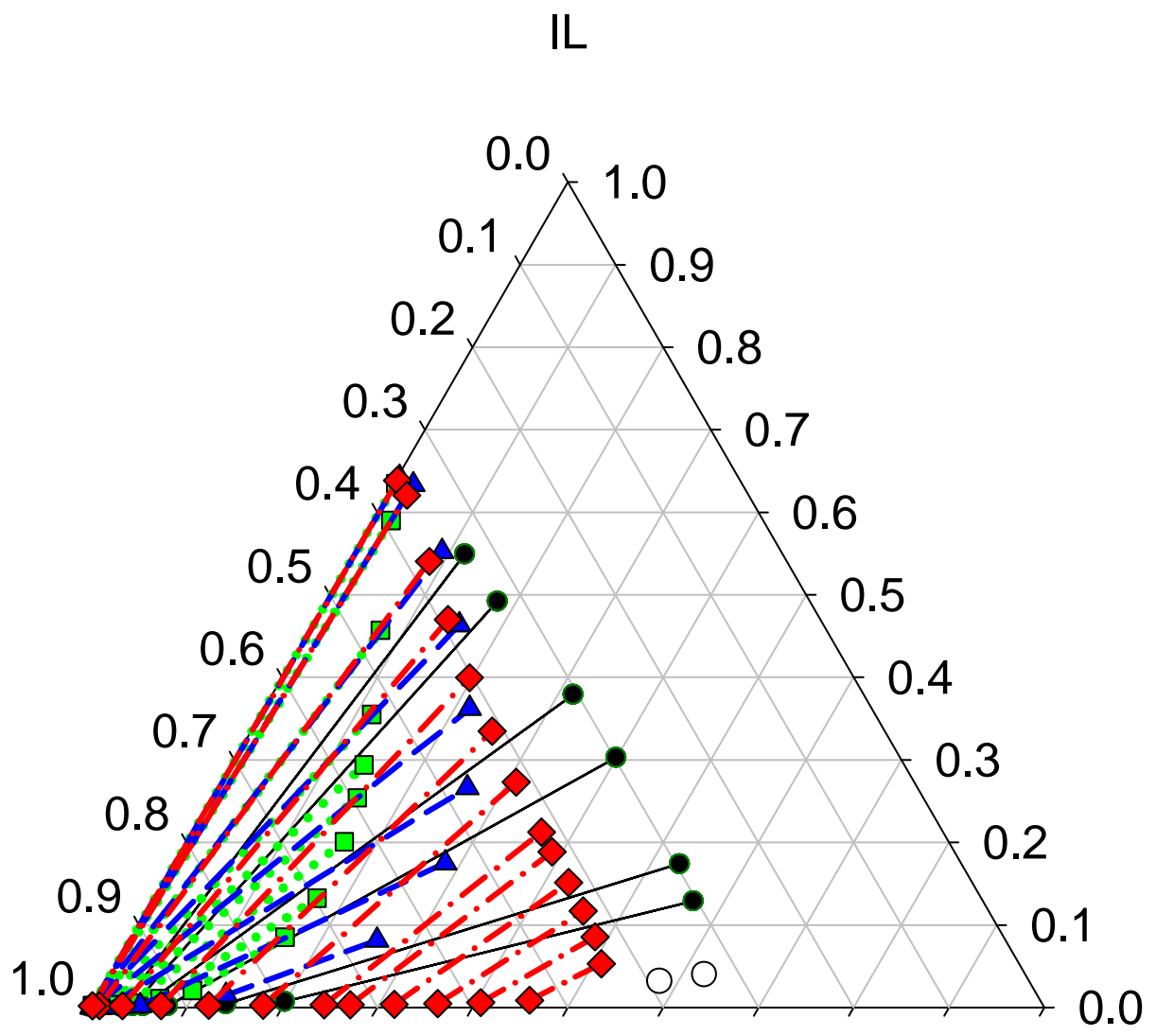

$\begin{array}{lllllllllllll}\text { THF } & 0.0 & 0.1 & 0.2 & 0.3 & 0.4 & 0.5 & 0.6 & 0.7 & 0.8 & 0.9 & 1.0 & \text { Water }\end{array}$

\begin{tabular}{|cl|}
\hline$\bullet-$ & Experimental tie lines \\
0 & Experimental cloud points \\
$\cdots$ & NRTL tie lines \\
$-\backsim-$ & UNIQUAC tie lines \\
$-\bullet \diamond-\cdot$ & eNRTL tie lines
\end{tabular}

Figure 1: Type 1 system $[\mathrm{emim}]\left[\mathrm{BF}_{4}\right] /$ Tetrahydrofuran/Water at $337 \mathrm{~K}$. Experimental data from Jork et al. ${ }^{19}$ All models predict Type 1 behavior. 


\section{$\mathrm{EtOH}$}

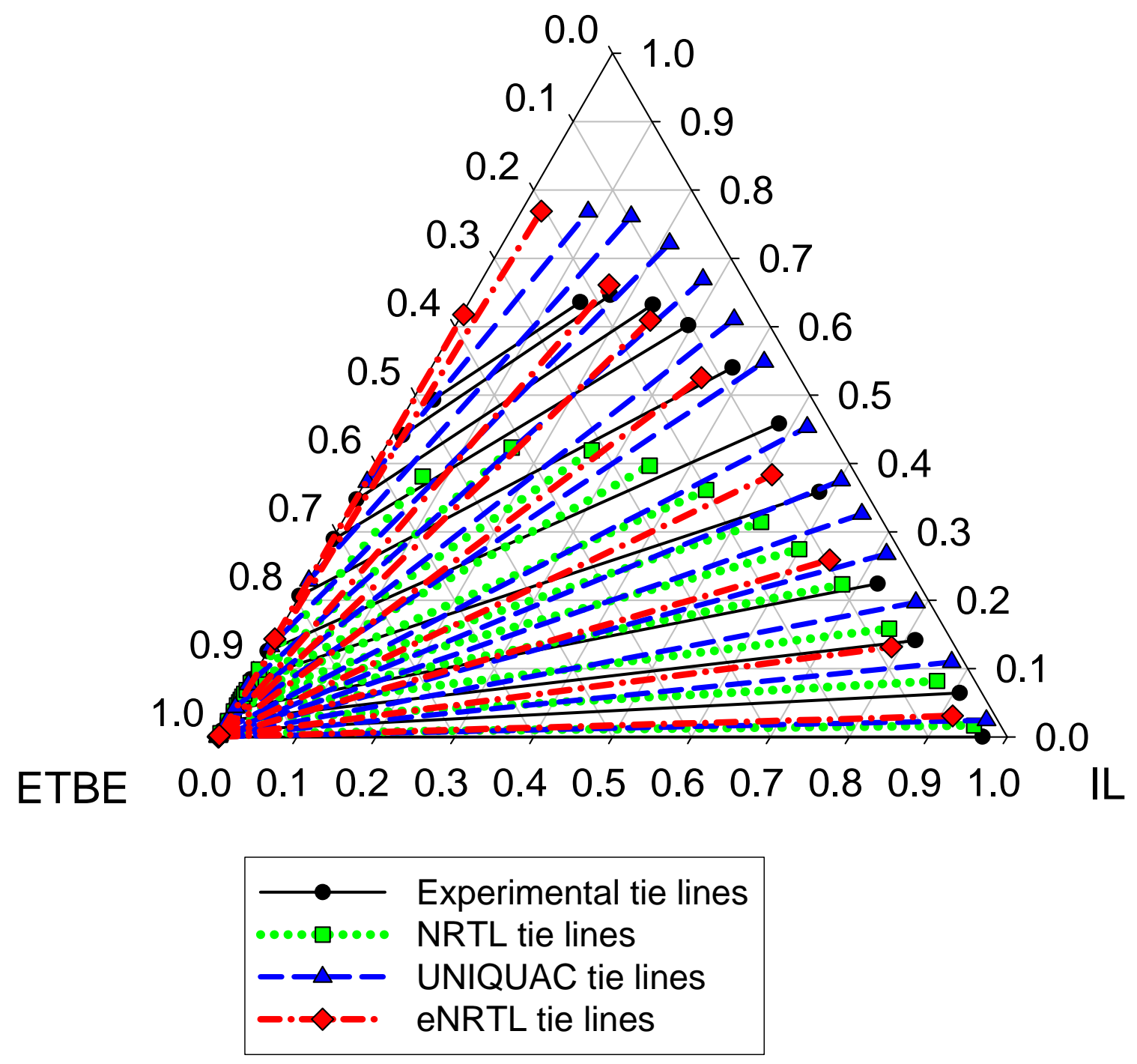

Figure 2: Type 1 system [emim] $\left[\mathrm{EtSO}_{4}\right] /$ Ethyl tert-butyl ether/Ethanol at $298 \mathrm{~K}$. Experimental data is from Arce et al. ${ }^{18}$ All models predict Type 1 behavior. 


\section{Benzene}

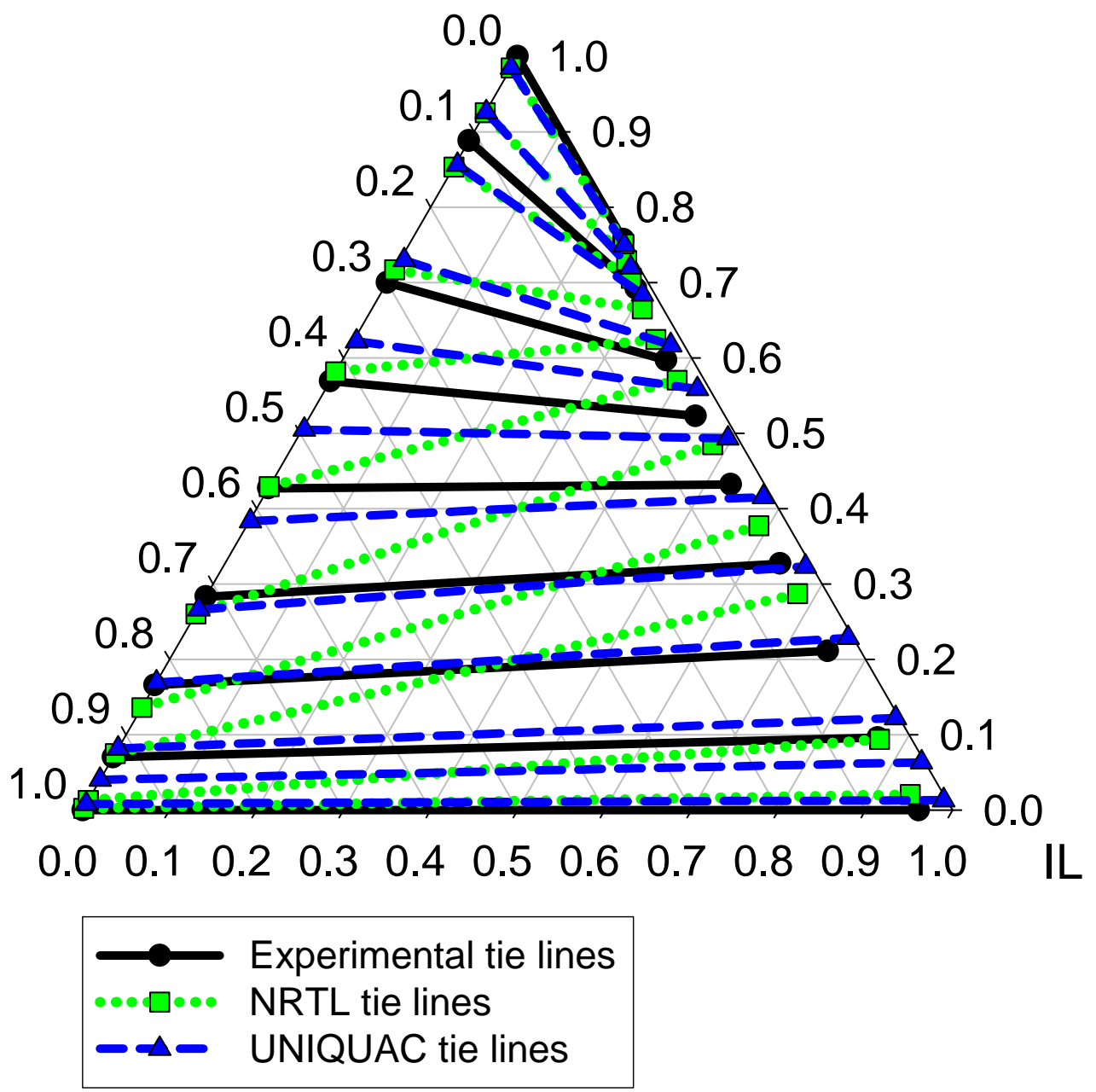

Figure 3: Type 2 system [emim] $\left[\mathrm{Tf}_{2} \mathrm{~N}\right] /$ Benzene/Hexane at $298 \mathrm{~K}$. Experimental data is from Arce et al. ${ }^{11}$ NRTL and UNIQUAC predict qualitatively correct Type 2 behavior. UNIQUAC is very accurate as well. 


\section{Benzene}

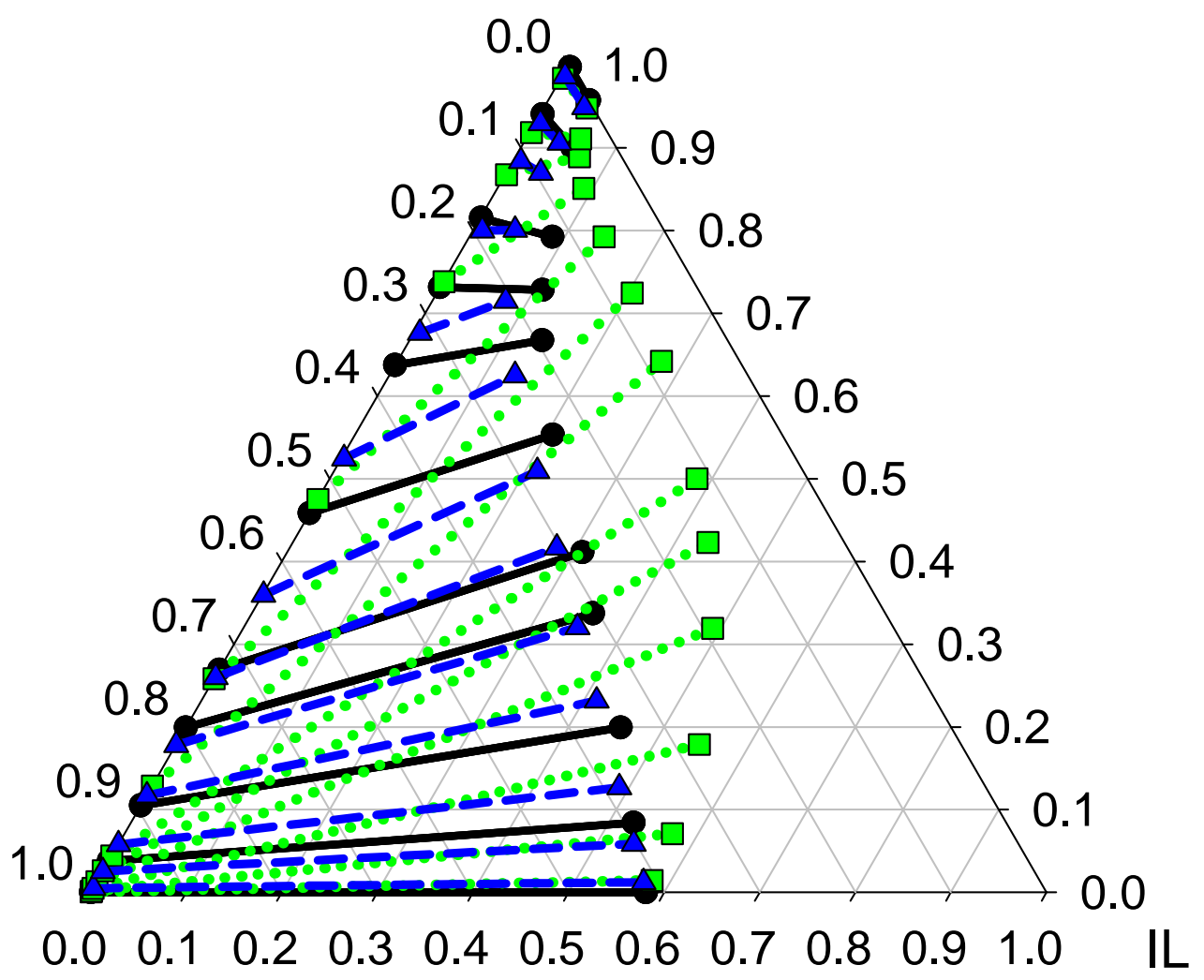

Hexane $\quad \begin{array}{llllllllllll}0.0 & 0.1 & 0.2 & 0.3 & 0.4 & 0.5 & 0.6 & 0.7 & 0.8 & 0.9 & 1.0 & \text { IL }\end{array}$

$\longrightarrow$ Experimental tie lines

.... NRTL tie lines

$\rightarrow-$ UNIQUAC tie lines

Figure 4: Type 2 system $[\mathrm{dmim}]\left[\mathrm{Tf}_{2} \mathrm{~N}\right] /$ Benzene/Hexane at $298 \mathrm{~K}$. Experimental data is from Arce et al. ${ }^{12}$ NRTL and UNIQUAC predict qualitatively correct Type 2 behavior. UNIQUAC is very accurate as well. 


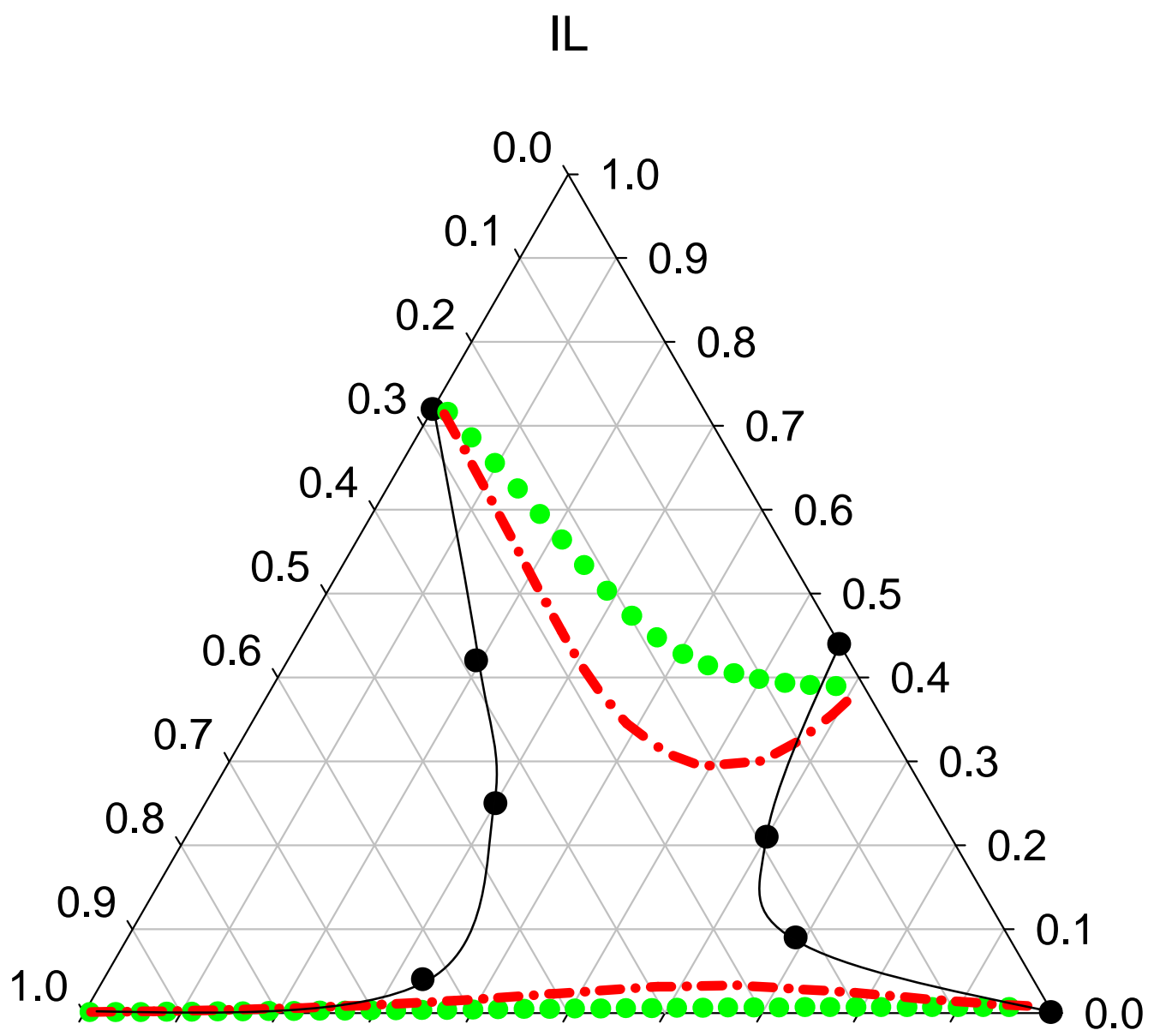

$\begin{array}{llllllllllllll}\text { Water } & 0.0 & 0.1 & 0.2 & 0.3 & 0.4 & 0.5 & 0.6 & 0.7 & 0.8 & 0.9 & 1.0 & \mathrm{EtOH}\end{array}$

\begin{tabular}{|ll|}
\hline$\bullet$ & Experimental binodal \\
\hdashline 000 & NRTL binodal \\
$-\bullet \cdot-$ & eNRTL binodal
\end{tabular}

Figure 5: Type 2a system $[\mathrm{bmim}]\left[\mathrm{PF}_{6}\right] /$ Ethanol/Water at $298 \mathrm{~K}$. Experimental data from Najdanovic-Visak et al. ${ }^{8}$ NRTL and eNRTL predict qualitatively incorrect Type 2 behavior. 


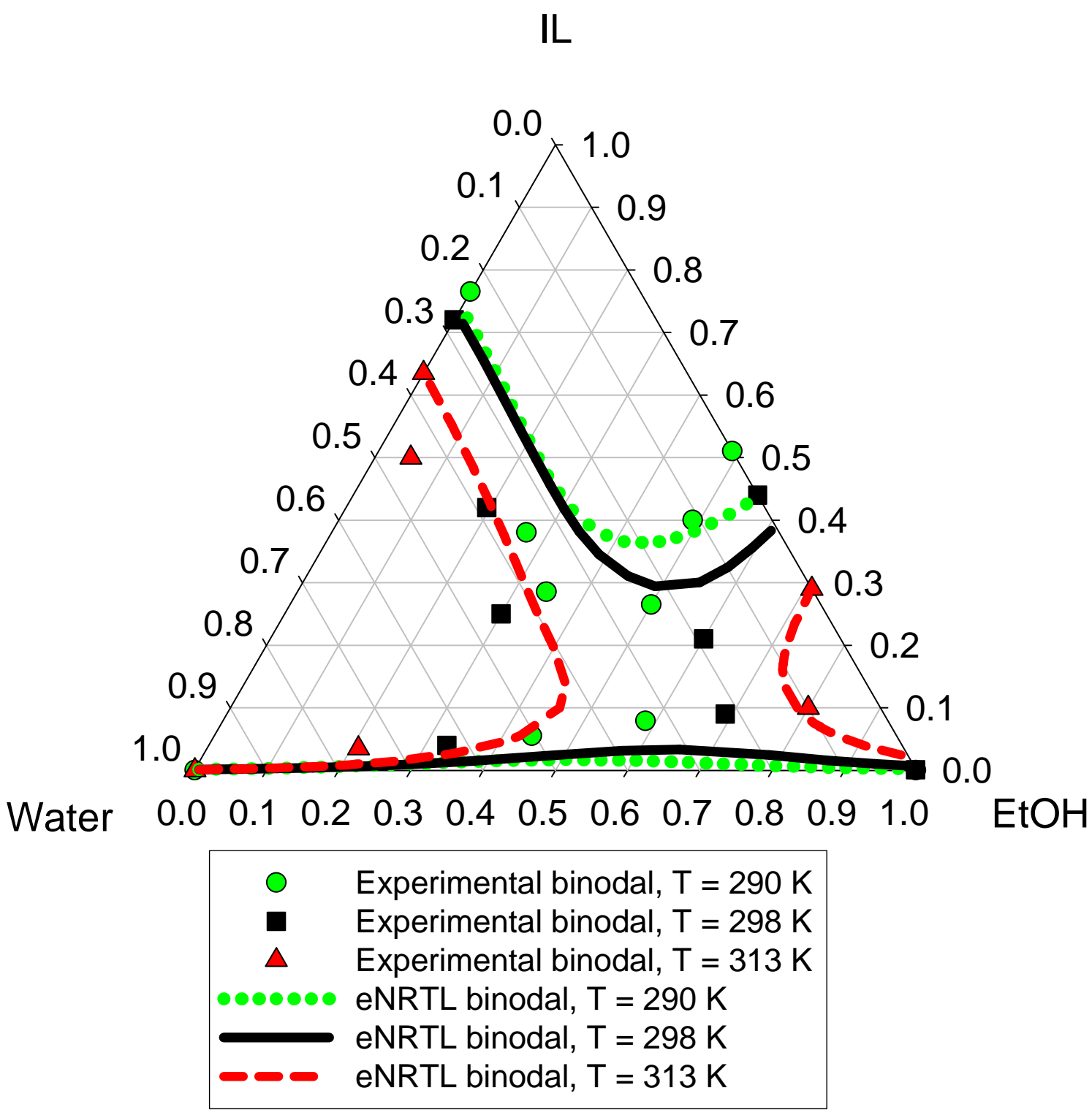

Figure 6: Type 2a system as $[\mathrm{bmim}]\left[\mathrm{PF}_{6}\right] /$ Ethanol/Water at 290, 298 and $313 \mathrm{~K}$. Experimental data from Najdanovic-Visak et al. ${ }^{8}$ eNRTL predicts an UCST between 298 and $313 \mathrm{~K}$, beyond which the correct Type $2 \mathrm{a}$ behavior is predicted. 


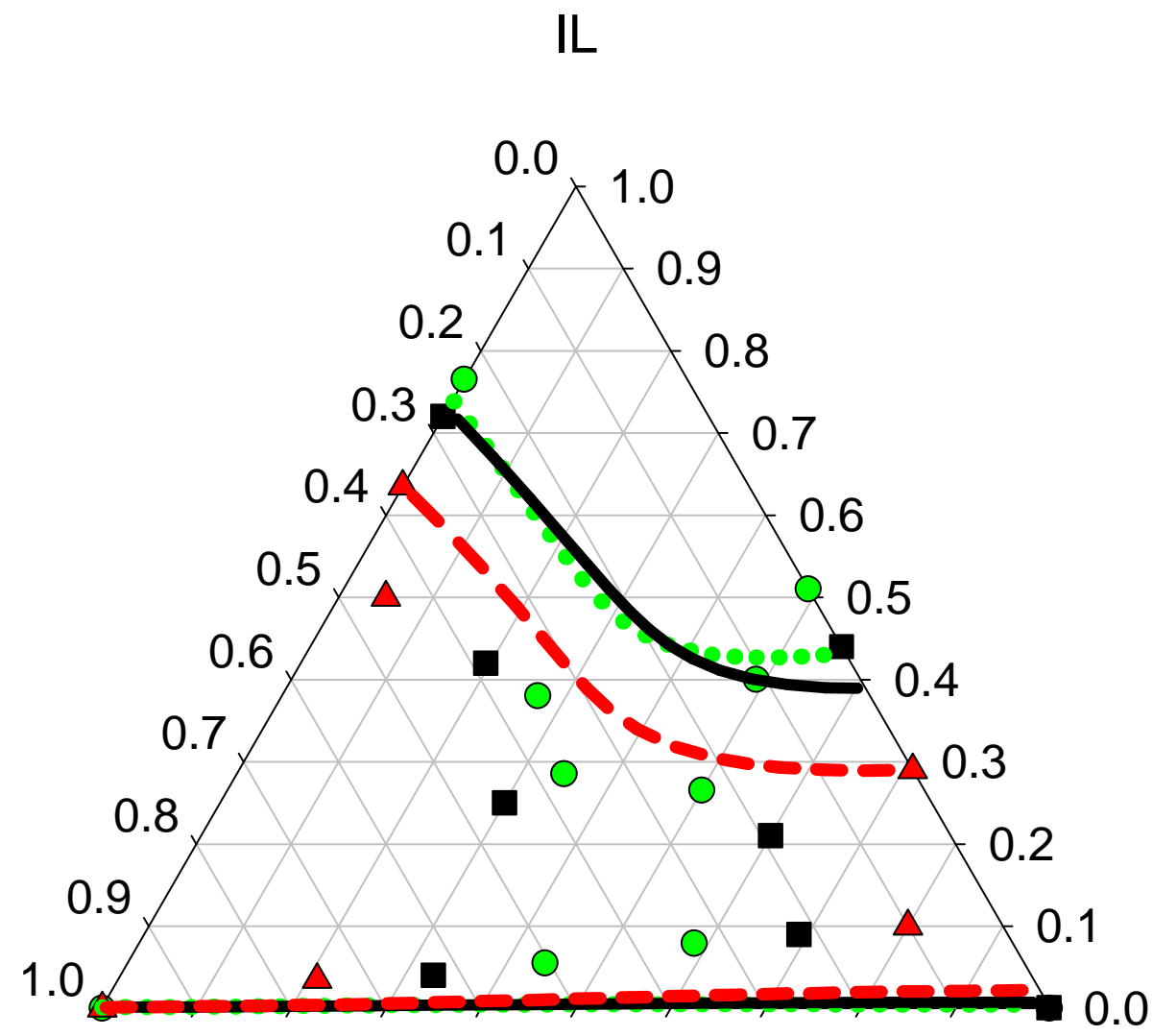

$\begin{array}{llllllllllllll}\text { Water } & 0.0 & 0.1 & 0.2 & 0.3 & 0.4 & 0.5 & 0.6 & 0.7 & 0.8 & 0.9 & 1.0 & \mathrm{EtOH}\end{array}$

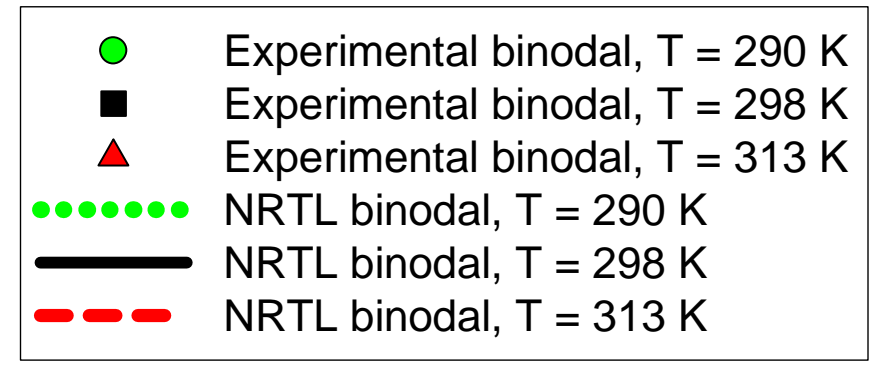

Figure 7: Type 2a system as $[\mathrm{bmim}]\left[\mathrm{PF}_{6}\right] /$ Ethanol/Water at 290, 298 and $313 \mathrm{~K}$. Experimental data from Najdanovic-Visak et al. ${ }^{8}$ NRTL predicts a Type 2 system at all temperatures. 


\section{Butanol}

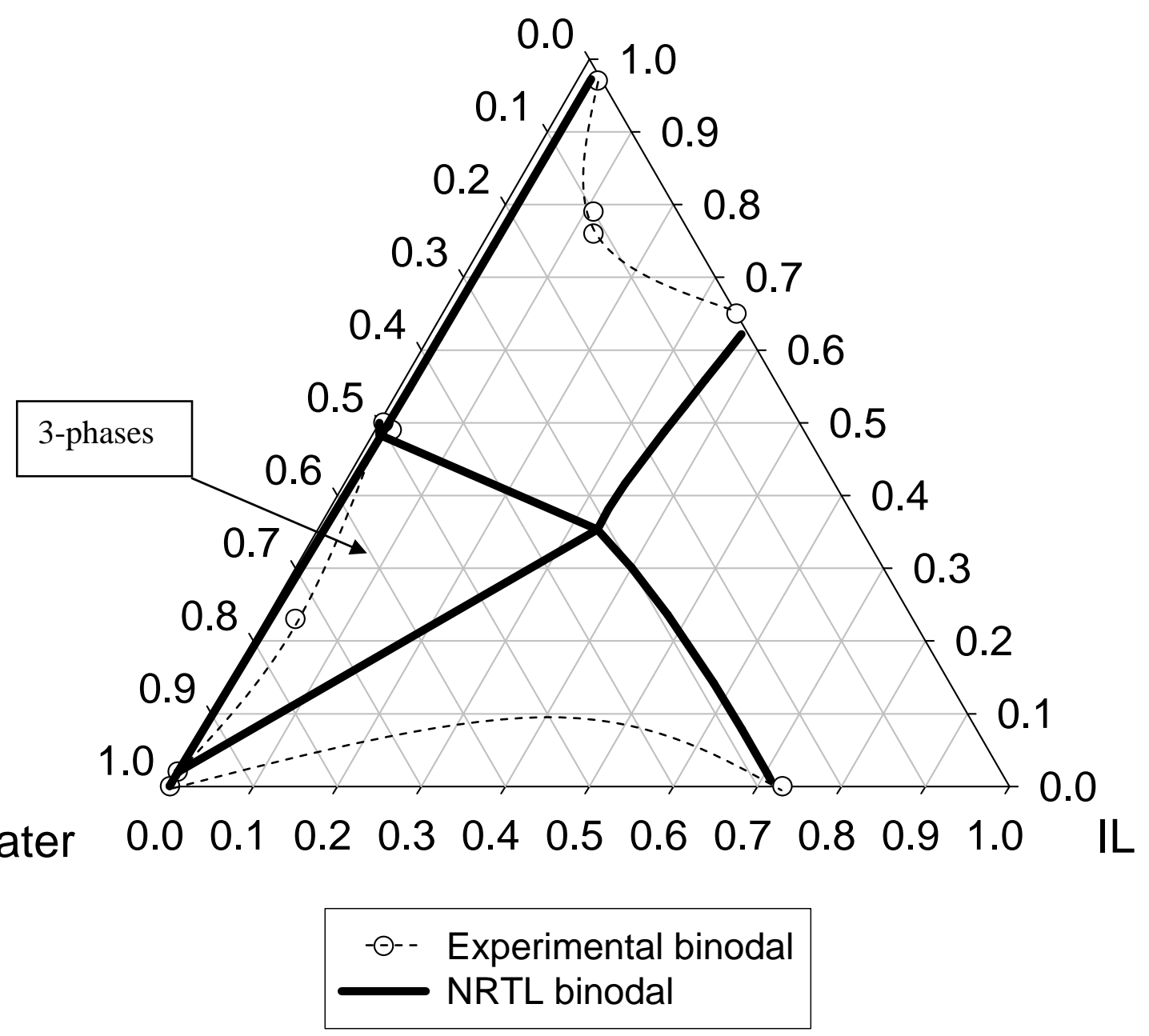

Figure 8: Type $3 \mathrm{~b}$ system as $[\mathrm{bmim}]\left[\mathrm{Tf}_{2} \mathrm{~N}\right] / \mathrm{n}$-Butanol/Water at $288 \mathrm{~K}$. Experimental data from Najdanovic-Visak et al. ${ }^{9}$ NRTL predicts qualitatively incorrect Type 3 behavior. 


\section{Butanol}

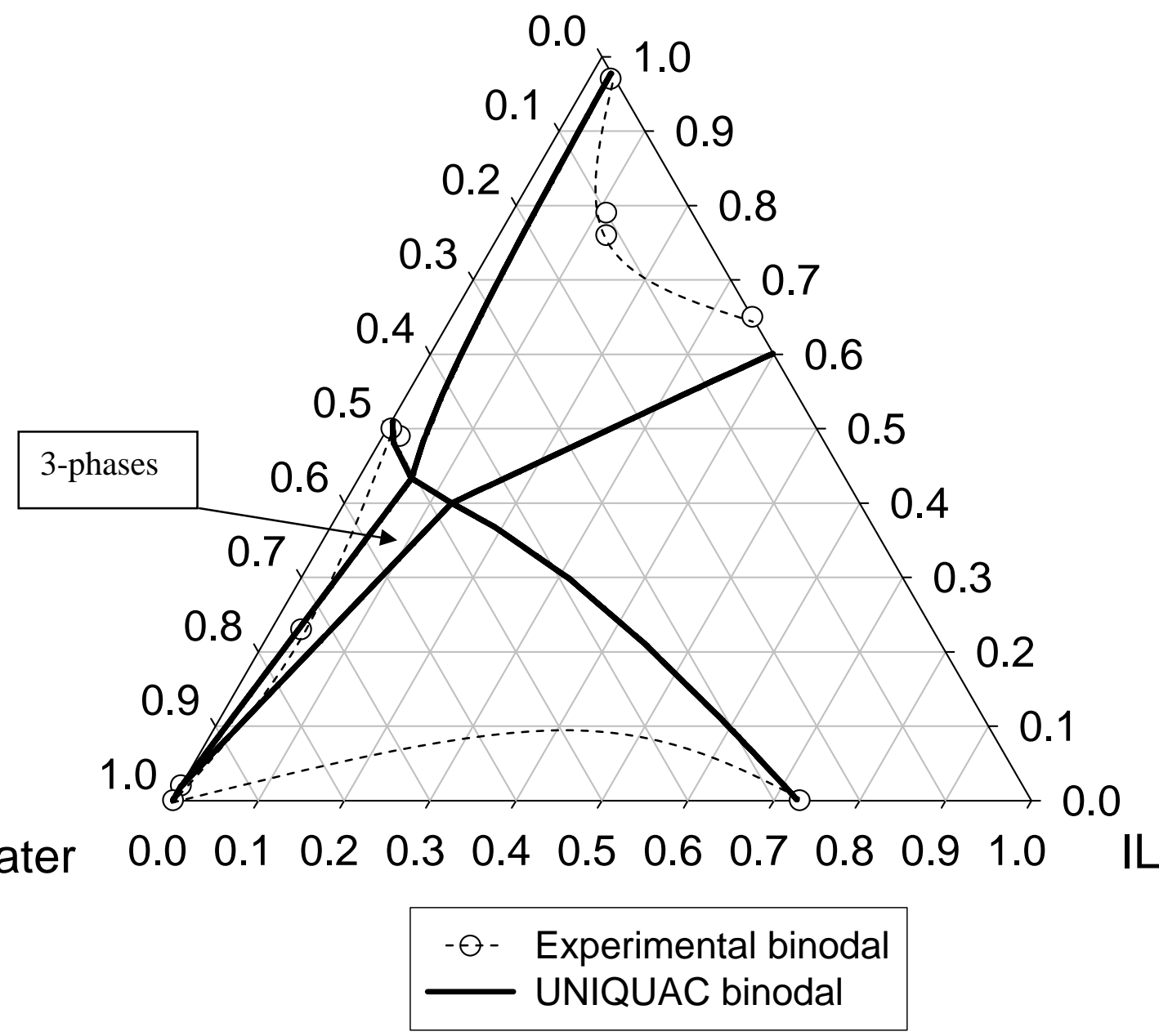

Figure 9: Type $3 \mathrm{~b}$ system as $[\mathrm{bmim}]\left[\mathrm{Tf}_{2} \mathrm{~N}\right] / \mathrm{n}-\mathrm{Butanol} / \mathrm{Water}$ at $288 \mathrm{~K}$. Experimental data from Najdanovic-Visak et al. ${ }^{9}$ UNIQUAC predicts qualitatively incorrect Type 3 behavior. 


\section{Butanol}

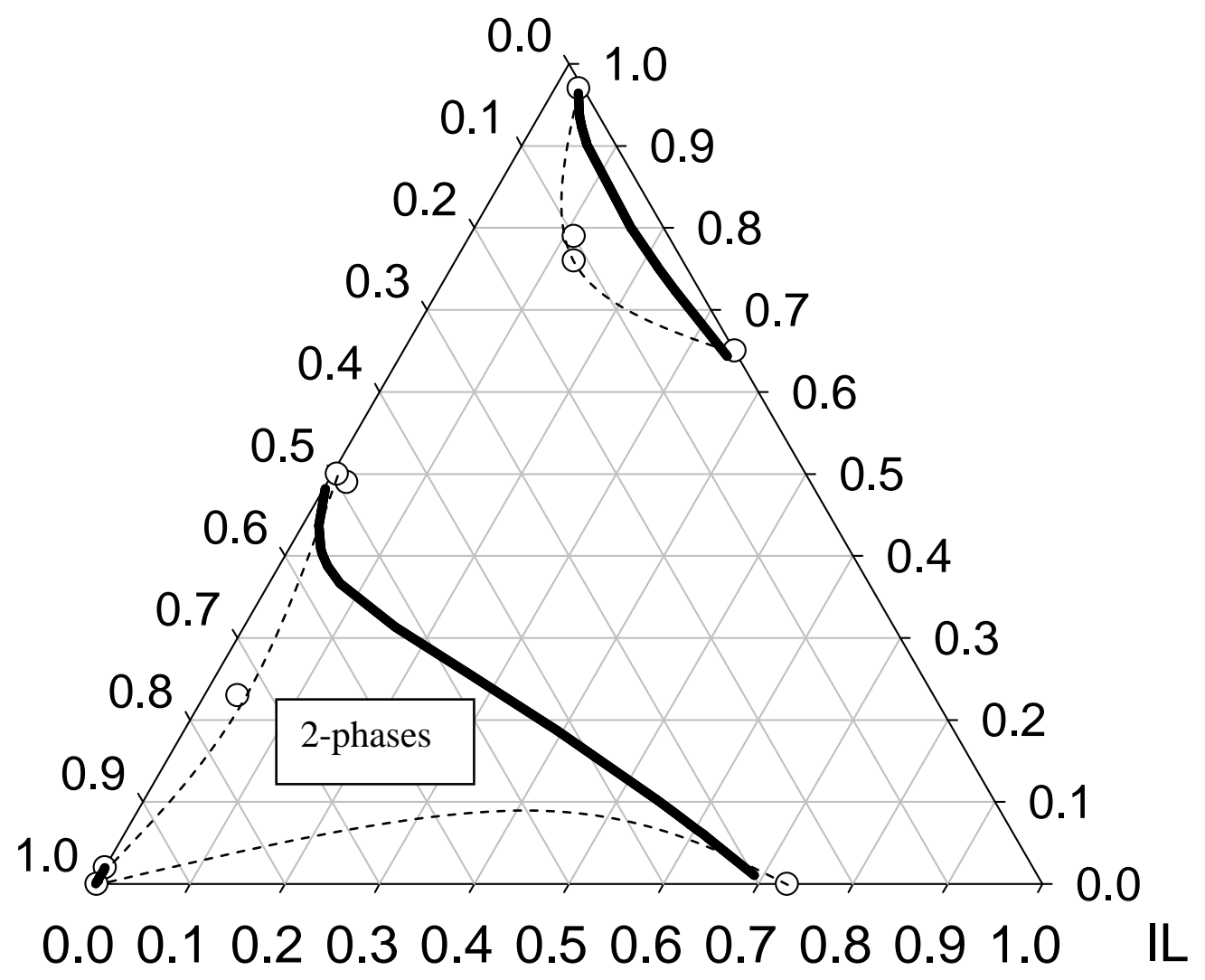

$\begin{array}{llllllllllllllll}\text { Water } & 0.0 & 0.1 & 0.2 & 0.3 & 0.4 & 0.5 & 0.6 & 0.7 & 0.8 & 0.9 & 1.0 & \text { IL }\end{array}$

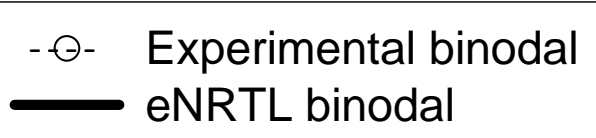

Figure 10: Type 3 b system as $[\mathrm{bmim}]\left[\mathrm{Tf}_{2} \mathrm{~N}\right] / \mathrm{n}-\mathrm{Butanol} / \mathrm{Water}$ at $288 \mathrm{~K}$. Experimental data from Najdanovic-Visak et al. ${ }^{9}$ eNRTL predicts qualitatively incorrect Type 3a behavior. 